\title{
Multivariate Statistical Analysis of Trace Elements in Pyrite: Prediction, Bias and Artefacts in Defining Mineral Signatures
}

\author{
Marija Dmitrijeva ${ }^{1}$, Nigel J. Cook ${ }^{1, *(\mathbb{D})}$, Kathy Ehrig ${ }^{2}{ }^{\circledR}$, Cristiana L. Ciobanu ${ }^{1}$, \\ Andrew V. Metcalfe ${ }^{3}$, Maya Kamenetsky ${ }^{4}$, Vadim S. Kamenetsky ${ }^{4}{ }^{(D)}$ and Sarah Gilbert ${ }^{5}$ \\ 1 School of Chemical Engineering and Advanced Materials, The University of Adelaide, Adelaide 5005, \\ Australia; marija.dmitrijeva@adelaide.edu.au (M.D.); cristiana.ciobanu@adelaide.edu.au (C.L.C.) \\ 2 BHP Olympic Dam, Adelaide 5001, Australia; kathy.ehrig@bhp.com \\ 3 School of Mathematical Sciences, The University of Adelaide, Adelaide 5005, Australia; \\ andrew.metcalfe@adelaide.edu.au \\ 4 School of Natural Sciences (Earth Sciences), University of Tasmania, Private Bag 79, Hobart 7001, Australia; \\ maya.kamenetsky@utas.edu.au (M.K.); dima.kamenetsky@utas.edu.au (V.S.K.) \\ 5 Adelaide Microscopy, The University of Adelaide, Adelaide 5005, Australia; sarah.gilbert@adelaide.edu.au \\ * Correspondence: nigel.cook@adelaide.edu.au
}

Received: 9 December 2019; Accepted: 6 January 2020; Published: 10 January 2020

\begin{abstract}
Pyrite is the most common sulphide in a wide range of ore deposits and well known to host numerous trace elements, with implications for recovery of valuable metals and for generation of clean concentrates. Trace element signatures of pyrite are also widely used to understand ore-forming processes. Pyrite is an important component of the Olympic Dam $\mathrm{Cu}-\mathrm{U}-\mathrm{Au}-\mathrm{Ag}$ orebody, South Australia. Using a multivariate statistical approach applied to a large trace element dataset derived from analysis of random pyrite grains, trace element signatures in Olympic Dam pyrite are assessed. Pyrite is characterised by: (i) a $\mathrm{Ag}-\mathrm{Bi}-\mathrm{Pb}$ signature predicting inclusions of tellurides (as PC1); and (ii) highly variable $\mathrm{Co}-\mathrm{Ni}$ ratios likely representing an oscillatory zonation pattern in pyrite (as PC2). Pyrite is a major host for As, Co and probably also Ni. These three elements do not correlate well at the grain-scale, indicating high variability in zonation patterns. Arsenic is not, however, a good predictor for invisible Au at Olympic Dam. Most pyrites contain only negligible Au, suggesting that invisible gold in pyrite is not commonplace within the deposit. A minority of pyrite grains analysed do, however, contain $\mathrm{Au}$ which correlates with $\mathrm{Ag}$, Bi and $\mathrm{Te}$. The results are interpreted to reflect not only primary patterns but also the effects of multi-stage overprinting, including cycles of partial replacement and recrystallisation. The latter may have caused element release from the pyrite lattice and entrapment as mineral inclusions, as widely observed for other ore and gangue minerals within the deposit. Results also show the critical impact on predictive interpretations made from statistical analysis of large datasets containing a large percentage of left-censored values (i.e., those falling below the minimum limits of detection). The treatment of such values in large datasets is critical as the number of these values impacts on the cluster results. Trimming of datasets to eliminate artefacts introduced by left-censored data should be performed with caution lest bias be unintentionally introduced. The practice may, however, reveal meaningful correlations that might be diluted using the complete dataset.
\end{abstract}

Keywords: pyrite; trace elements; multivariate statistics; left-censored data; Olympic Dam 


\section{Introduction}

Pyrite $\left(\mathrm{FeS}_{2}\right)$ is by far the most common sulphide mineral on Earth [1]. It is stable in geological environments ranging from low to high temperatures and at a wide range of pressures (e.g., [2]). Pyrite is also a robust, refractory mineral that can readily record successive stages of growth, which are expressed both by preserved textures and trace element signatures. Natural pyrite commonly incorporates a wide range of elements within its structure, notably $\mathrm{As}, \mathrm{Co}$ and $\mathrm{Ni}$, whereas several others, such as $\mathrm{Cu}, \mathrm{Tl}$ and $\mathrm{Ag}$, are more rarely reported at concentrations ranging from sub-ppm levels to as much as several wt.\%. Interest in the trace element content of pyrite goes back to the 1940s [3-5], pre-dating electron probe microanalysis or other newer methods of trace element analysis with sensitivities in the ppm range, including laser ablation inductively coupled plasma mass spectrometry (LA-ICP-MS). Such chemically 'impure' pyrites may display subtly different physical properties (e.g., [6]) and elevated trace element contents may also impact on pyrite behaviour during mineral processing (e.g., [7]).

Trace element signatures in pyrite are used in ore deposit studies to constrain ore genesis, making pyrite one of the most studied minerals. Such signatures are used as tools to distinguish pyrite with different origins, to interpret fluid evolution, and to track the physicochemical conditions of hydrothermal mineral systems (e.g., [8-13], and many others).

Due to its relative abundance-commonly the dominant sulphide in many types of base and precious metal ores-pyrite is also an important, and in some cases the dominant host for several elements of economic importance, notably gold [14,15]. Pyrite can, however, also host a range of elements that are deleterious to processing, or which carry significance from an environmental perspective. Release of elements like $\mathrm{Hg}$, or particularly $\mathrm{Tl}$, [16-18] from pyrite can have major ramifications for environmental management around mine sites.

Advances in multi-element trace element analysis, particularly by LA-ICP-MS, have generated a substantial body of literature on the trace element chemistry of pyrite from a wide range of different deposits [19]. Moreover, trace element mapping by LA-ICP-MS has enabled the correlation of trace element signatures with mineral textures at the micron-scale. Although widely used and trusted, LA-ICP-MS does have the relative disadvantage of sampling relatively large volumes of material (compared, for example, to electron probe microanalysis) - a trade-off with the generally excellent sensitivity of the technique. Thus, LA-ICP-MS data cannot readily distinguish between those elements contained within the mineral lattice and elements present as inclusions of discrete minerals when those inclusions are too small and/or homogeneously distributed to be seen using other methods. Studies have emerged in recent years (e.g., [20-22]) showing, based on evidence from different minerals, that elements considered-or often taken for granted-as being lattice-bound in a given mineral, may actually occur in the form of included phases as fine particles (up to thousands of $\mathrm{nm}$ ), or nanoparticles $(<100 \mathrm{~nm})$ that are only visible by using advanced transmission electron microscopy methods (e.g., [23-25]).

The ease of data generation by LA-ICP-MS has also led to datasets becoming larger, necessitating more sophisticated statistical techniques to recognize and interrogate patterns within the data. Multivariate statistical analysis can significantly complement the conventional ways of looking at mineral chemistry data by identifying associations among elements and grouping geochemical analyses into meaningful and interpretable clusters. Such an approach is reproducible, quantitative and not subjective (e.g., [26-29]).

Many data analysis techniques require complete data sets. A common problem, and one that is exacerbated when applying multivariate statistics to large datasets, is how to adequately treat concentration data that fall below the minimum detection limit ( $\mathrm{mdl}$ ). In geochemical data analysis, it is common to replace mdl values with a fraction of that value, for instance one half of mdl, or a fixed value, e.g., the mean or median, however, this approach is to be avoided as it changes the relative variation structure in compositions [30,31], especially when the number of affected samples is a significant percentage of the total. The exclusion of such values is not recommended either, as it results in significant loss of valuable information and bias when estimating parameters like mean and/or median. 
For these reasons, sensible imputation of left-censored data is a preferred option. For geochemical (i.e., compositional) data, there are several available imputation algorithms which include, but are not limited to, model-based methods like expectation-maximisation (EM) and multiplicative lognormal replacement algorithm [30], as well as distance-based k-nearest neighbour where the information of the nearest complete observations is used to estimate the left-censored values [32].

This contribution addresses the trace element chemistry of pyrite in the giant Olympic Dam Cu-U-Au-Ag deposit, South Australia [33], the largest iron-oxide copper gold (IOCG) deposit on Earth. Published data for trace elements in pyrite from IOCG systems are relatively limited despite the fact that it is abundant and a potential host for metals of importance (e.g., [34-36]). There are also only few published examples of multivariate statistical analyses applied to pyrite data (e.g., [37,38]), although the potential application of multivariate statistical methods to issues of acid mine drainage has been recently recognised [39].

This study is significant in that it is based on a large suite of LA-ICP-MS analyses (almost 5000 analyses) of pyrite in relatively high-copper grade ores $(>2 \% \mathrm{Cu})$ from across the deposit. Routine analysis of key minerals is undertaken by BHP Olympic Dam and this dataset was compiled from several individual batches acquired over a period of three years. Pyrite is the second most abundant sulphide in the Olympic Dam deposit, making up, on average, $0.46 \%$ of orebody (after chalcopyrite, $0.93 \%$, and before bornite, $0.33 \%$ [33]). Across the deposit, pyrite typically occurs alone or is replaced by chalcopyrite, at sizes ranging from relict pyrite no more than a few microns in size, replaced by chalcopyrite, to cm-sized euhedral cubes.

The research presented below carries two main objectives. Firstly, we determine which elements occur in pyrite, and what are their typical concentration levels and ranges. Although it is impossible to quantify the proportion of a given element within the mineral lattice or as inclusions of discrete minerals, statistical analysis (Principal Component Analysis, PCA) allows identification of groups of elements with strong correlation with one another that can be further discussed in terms of their physical state within pyrite. For example, elevated concentrations of chalcophile group elements $(\mathrm{Ag}, \mathrm{Pb}, \mathrm{Bi}, \mathrm{Te}, \mathrm{Se})$ that show a correlation with $\mathrm{Au}$ but not with As are likely to be present as discrete tellurides rather than being directly incorporated in the crystal lattice. Such prediction of mineral inclusions is impossible with bivariate plots alone, or from down-hole time-resolved LA-ICP-MS spot analysis depth profiles, if the inclusions are sufficiently small. We go on to discuss the implications these data may have for understanding deportment models for elements of economic interest (e.g., $\mathrm{Au}, \mathrm{Ag}$ ), deleterious elements of concern that need monitoring in the processing circuit (such as As), and also diverse elements that are of interest with respect to longer-term recovery potential (e.g., Co, Te, and Se).

Secondly, the large size of our dataset allows us to demonstrate how the common practice of excluding a percentage of analytical data because they yield values below mdl for multiple trace elements (left-censored values) can impact on the overall results and the interpretations reached. Values below detection limit are almost always present in geochemical datasets-yet are often neglected, poorly understood, or inadequately interpreted.

\section{Approach, Methods and Data Treatment}

\subsection{Data Acquisition}

Although Olympic Dam pyrite displays considerable diversity with respect to petrography, mineral assemblage and texture [33], acquisition of spot analyses for this study was intentionally done without recording pyrite textures. This approach was taken since choosing a particular location within a grain for a spot analysis can, often inadvertently, result in biased datasets which may include overand undersampled textural varieties, and implicitly, their geochemical attributes.

To ensure that pyrite grains were analysed blindly (i.e., without bias or pre-selection on the basis of ore textures or ease of microanalysis), analyses of 145 samples of sulphide-bearing diamond drill 
core samples, spatially located across the deposit, composited over 20 m-lengths (crushed/milled to $100 \%$ passing $1 \mathrm{~mm}$ ) from Olympic Dam were considered. This implies that analysed pyrite grains can belong to any type of pyrite from anywhere in the deposit under the single constraint that they are from high-copper grade ores $(>2 \% \mathrm{Cu})$. LA-ICP-MS spot analyses were acquired on randomly selected pyrite grains from these samples and analysed for a wide suite of elements. Due to the nature of the crushed/milled samples, there is no subjective bias in sample collection, thus making these data absolutely representative of pyrite in sulphide ores from Olympic Dam containing $>2 \% \mathrm{Cu}$. A second advantage of using data acquired on crushed/milled drill core composites is the lack of intra-sample correlation, which is often the case for LA-ICP-MS data, where mineral grains derived from a single sample show highly similar chemistry (e.g., [35]). A third advantage is the fact that the samples have been milled, thus reducing - though not completely avoiding the issue of obtaining representative data on strongly zoned grains by analysis only of clean (inclusion-free) domains.

All analysis was undertaken RESOlution-LR $193 \mathrm{~nm}$ ArF excimer laser with a large format S155 ablation cell (Laurin Technic Inc., Narrabundah, Australia), coupled to an Agilent 7500cs Quadrupole ICP-MS at the University of Tasmania, Hobart, Australia. Laser spot size varied from 19 to $33 \mu \mathrm{m}$. Isotopes measured were ${ }^{27} \mathrm{Al},{ }^{34} \mathrm{~S},{ }^{47} \mathrm{Ti},{ }^{55} \mathrm{Mn},{ }^{57} \mathrm{Fe},{ }^{59} \mathrm{Co},{ }^{60} \mathrm{Ni},{ }^{65} \mathrm{Cu},{ }^{66} \mathrm{Zn},{ }^{75} \mathrm{As},{ }^{77} \mathrm{Se},{ }^{89} \mathrm{Y},{ }^{90} \mathrm{Zr},{ }^{95} \mathrm{Mo}$, ${ }^{109} \mathrm{Ag},{ }^{111} \mathrm{Cd},{ }^{118} \mathrm{Sn},{ }^{121} \mathrm{Sb},{ }^{125} \mathrm{Te},{ }^{140} \mathrm{Ce},{ }^{157} \mathrm{Gd},{ }^{172} \mathrm{Yb},{ }^{178} \mathrm{Hf},{ }^{181} \mathrm{Ta},{ }^{182} \mathrm{~W},{ }^{185} \mathrm{Re},{ }^{197} \mathrm{Au},{ }^{204} \mathrm{~Pb},{ }^{205} \mathrm{Tl},{ }^{206} \mathrm{~Pb}$, ${ }^{207} \mathrm{~Pb},{ }^{208} \mathrm{~Pb},{ }^{209} \mathrm{Bi},{ }^{232} \mathrm{Th},{ }^{235} \mathrm{U}$ and ${ }^{238} \mathrm{U}$.

The ca. 5000 spot analyses were collected in 28 batches. Ablation consisted of $20 \mathrm{~s}$ of gas background collection followed by $40 \mathrm{~s}$ of spot ablation. Calibration routines considered both primary reference materials, STDGL3 and STDGL2b2 [40], depending on a particular batch, and the secondary GSD-1G (US Geological Survey) glass reference material. Standard measurements were performed at the beginning and at the end of each analysis round of $\sim 20$ to 25 spot analyses. All the data reduction was performed in LADR 1.0.09 [41]. Iron was the internal calibration element and ideal stoichiometry was assumed.

Four $\mathrm{Pb}$ isotopes were measured in order to fingerprint radiogenic and natural $\mathrm{Pb}$ in pyrite. The deposit is uranium-bearing and a greater part of the lead in the deposit is the radiogenic product of uranium decay. Nevertheless, galena with a clear non-radiogenic signature is also noted [42]. For this reason, $\mathrm{Pb}^{204}, \mathrm{~Pb}^{206}, \mathrm{~Pb}^{207}$ and $\mathrm{Pb}^{208}$ were measured separately, with data calculated based on a $1595 \mathrm{Ma}$ age. Below, the notation ${ }^{\mathrm{X}} \mathrm{Pb}$ is used to refer to all four lead isotopes unless specified otherwise.

\subsection{Data Quality Control, Trimming and Imputation}

Each time-resolved LA-ICP-MS depth profile was carefully checked for the presence of contaminating phases, e.g., REE- and U-bearing minerals, hematite, or $\mathrm{Cu}$-(Fe)-sulphides, all of which commonly occur as inclusions in pyrite at Olympic Dam. As a second step to improve data quality, all rows containing anomalous/extreme values for all elements (but especially $\mathrm{Cu}$ ), were excluded to make the data representative of pyrite without admixtures of $\mathrm{Cu}-(\mathrm{Fe})$-sulphides. The $\mathrm{Cu}$ threshold was defined as $>5000 \mathrm{ppm}$.

Sulphur was not considered in the subsequent data analysis; likewise, $\mathrm{Cd}, \mathrm{Sb}$ and $\mathrm{Tl}$ which displayed only a very small number of values above mdl. A range of elements that are not expected to be incorporated into the pyrite lattice were also excluded from the data: $\mathrm{Al}, \mathrm{Ce}, \mathrm{Gd}, \mathrm{Hf}, \mathrm{Ta}, \mathrm{Th}$, $\mathrm{Y}, \mathrm{Yb}$ and $\mathrm{Zr}$. Other elements, notably $\mathrm{U}, \mathrm{W}$ and $\mathrm{Mo}$, were also not included in the data. These elements, characteristically associated with each other, are attributable to nano- and microinclusions of hematite, the dominant gangue mineral at Olympic Dam [33] and often as U-W-Sn-Mo-bearing hematite $[43,44]$. Nonetheless, when included into PCA, these elements strongly dominate the first principal component (PC1).

In order to investigate the effects of left-censored data on the statistical analyses and interpretation, the original dataset was trimmed to reduce the overall number of values that fall below the detection limit. Therefore, three datasets are considered further: a first comprising all 4926 spot analyses; and a second and third with 1501 and 525 analysis spots, respectively. The $\mathrm{N}=4926$ data contain $43 \%$ 
of left-censored values overall, with at least half the elements having $>50 \%$ of left-censored cases (Figure 1a). The $\mathrm{N}=1501$ data were obtained by trimming the $\mathrm{N}=4926$ dataset on the condition of retaining only those analyses that have less than six left-censored values per analysis (i.e., per row) resulting in a new sub-set that contains only $23 \%$ of left-censored cases overall (Figure 1b). Finally, the $\mathrm{N}=525$ data were obtained based on the condition of only retaining analyses that have three or less left-censored values per row-giving a still smaller subset with an overall of $12 \%$ of data being left-censored (Figure 1c). Such consecutive trimming results in the smaller datasets having more complete analyses—but, implicitly, slightly higher overall concentrations for all analysed elements.

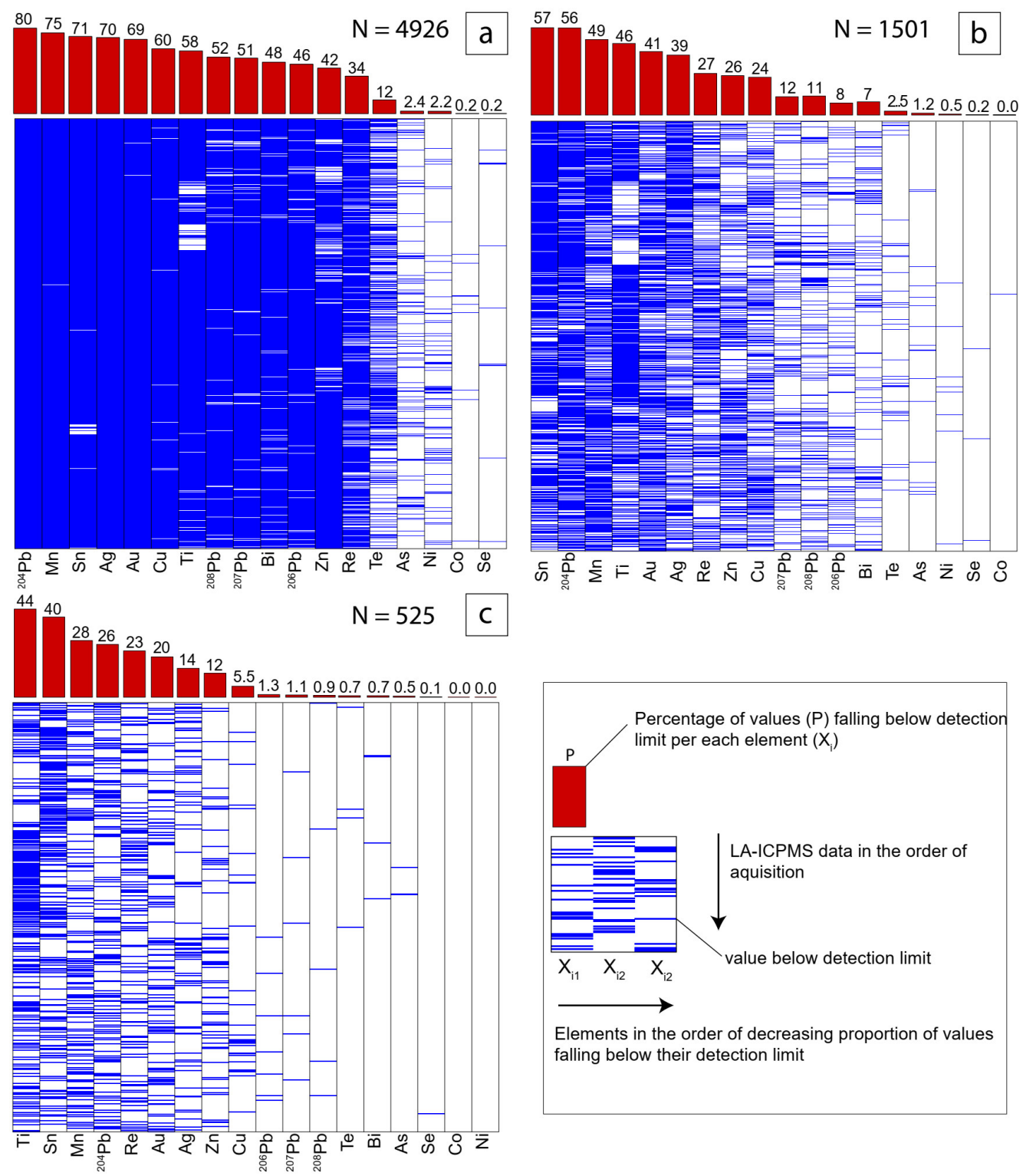

Figure 1. Schematic visualisation of measured and below mdl values for the (a) $N=4926$, (b) $N=1501$ and (c) $\mathrm{N}=525 \mathrm{LA}-\mathrm{ICP}-\mathrm{MS}$ pyrite datasets presented, from top to bottom, in the sequence of acquisition. The percentage of values being below detection limit is given for each element.

The imputation of left-censored data was done for each of the three datasets individually using multiplicative lognormal replacement from the R package 'zCompositions' [31]. We also attempted to employ an expectation-maximisation algorithm from the same package, a method that imputes values based on analyses without left-censored data. The algorithm did not produce the expected replacements due to the large amount of such values in the complete $(\mathrm{N}=4926)$ dataset. The outcome 
of multiplicative lognormal replacement was assessed via quantile-quantile and bivariate plots to assess the appropriateness of the replacement. An example of such assessment and comparison with deterministic imputation strategies (i.e., taking absolute mdl values, or replacing by a half and median) is given in Figure 2.

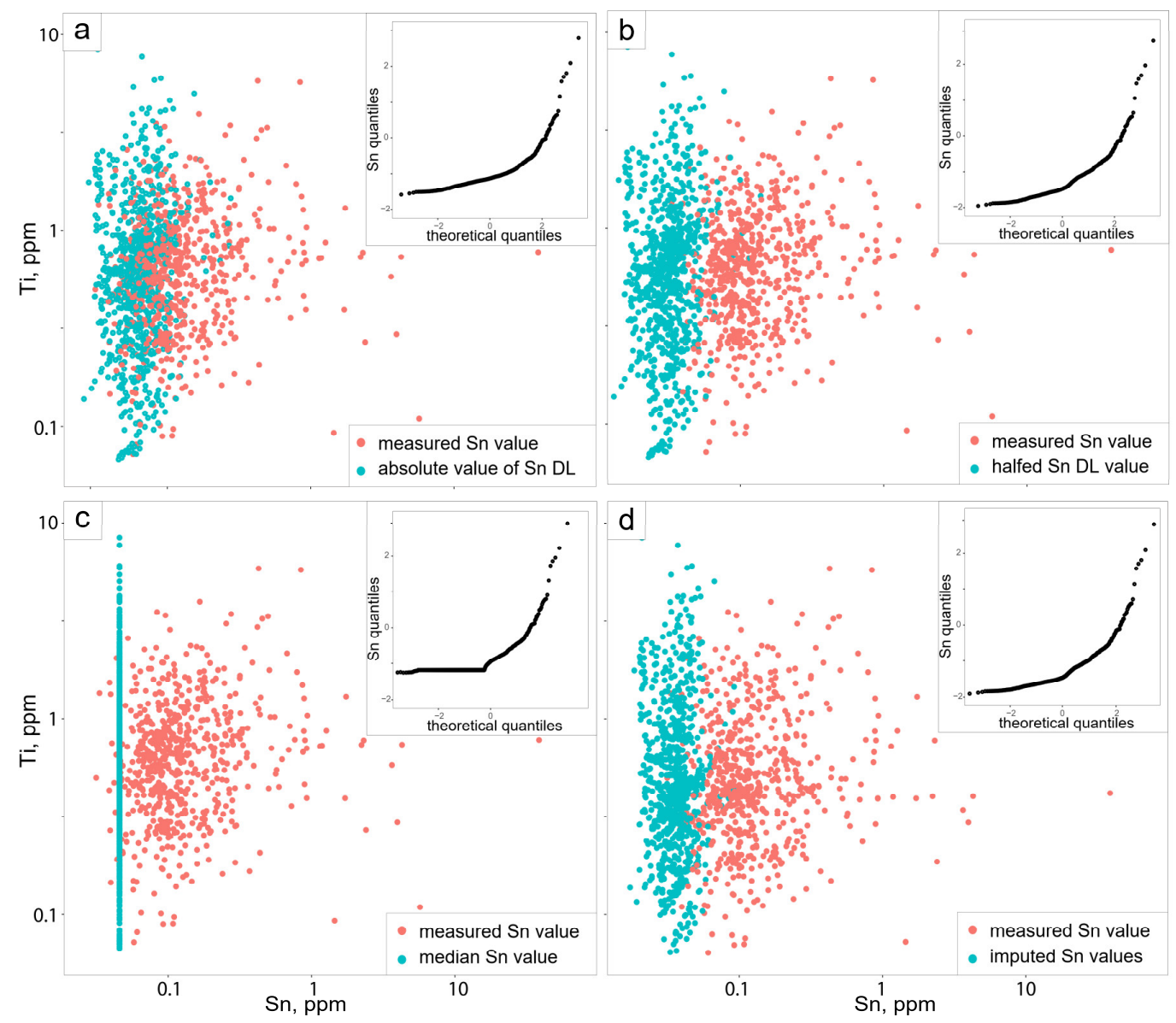

Figure 2. Quantile-quantile plots of $\mathrm{Sn}$ and bivariate plots of log-transformed $\mathrm{Sn}$ versus Ti in ppm from the $\mathrm{N}=1501$ dataset illustrating the effect of (a) taking absolute values of the detection limit, (b) division of a detection limit value by two, (c) fixed value imputation, e.g., median (calculated from the imputed dataset) and (d) multiplicative lognormal replacement. Note the similarity between b and $d$ and the narrower range of imputed $S n$ values for $d$. Note that fixed value imputation results in asymmetric Sn distribution.

\subsection{Multivariate Analyses}

Multivariate statistical analyses were applied to each of the three datasets using the compositional data approach $[45,46]$. The techniques used included Principal Component Analysis (PCA) applied to the centred log-ratio(clr)-transformed data; k-means clustering applied to the isometric log-ratio(ilr)-transformed data, and hierarchical cluster dendrogram obtained from the Aitchison variation matrix generated for each of the thee datasets [46]. Additionally, multiple linear regression was fitted to obtain the quantitative relationships of Au to all the other elements.

Both clr- and ilr-transformations were performed using the R package 'compositions' [47]. The ilr transformation $[48,49]$ was performed for each dataset using the $\mathrm{R}$ 'balanceBase ()$^{\prime}$ function, which employed sequential binary partitioning of the D-part composition following the D-1 steps, whereas the steps of partitioning corresponded to the splits of the corresponding hierarchical dendrogram (Supplementary Material A; Tables S1-S3). The necessity of data transformations and Aitchison variation matrix is justified by the specific properties of geochemical data which only carry relative 
information and sums up to a given constant, for instance, $100 \mathrm{wt}$ \% or one million ppm [45]. Although trace element data accounts for a small percentage of the bulk composition and a log-ratio vector of trace element concentrations $\left[\ln \frac{x_{1}}{X}, \ln \frac{x_{2}}{X}, \ldots, \ln \frac{x_{D}}{X}\right]$ may be close to $\left[\ln \left(x_{1}, x_{2}, \ldots, x_{D}\right)\right]$, where $X=\sum_{i=1}^{D} x_{i}$ [50], the statistical analyses with log-transformed and raw data was avoided. This is because the PCA applied to the log-transformed data results in spurious patterns on biplots (e.g., [42,51]). However, visualisation of distributions for specific elements was done using boxplots applied to log-transformed concentrations.

The co-dependence between all possible pairs of elements will be investigated by using an Aitchison variation matrix $(\mathrm{T})$, where the components of this $\mathrm{D} \times \mathrm{D}$ variation matrix are the variances of the $\log$-ratios of all the possible pairs of elements, with $i, j=1, \ldots, \mathrm{D}$ and $\tau_{i j}$ obtained by

$$
\tau_{i j}=\operatorname{var}\left(\ln \left(\frac{x_{i}}{x_{j}}\right)\right)
$$

Such variation matrix is used as a measure of similarity within elements for the hierarchical clustering algorithm. The results are presented as a dendrogram, reflecting the associations and geochemical affinities or dissimilarity among the groups of elements in a large dataset.

Under the compositional approach, both PCA and k-means clustering are efficient at underpinning element associations as groups, and clusters, i.e., analyses characterised by similar chemistry. These statistical analyses are often used for orebody characterisation and geochemical domaining [52], but the same methods are transferrable to LA-ICP-MS datasets. The k-means clustering is a versatile and simple iterative algorithm that aims at partitioning geochemical analyses into $\mathrm{k}$ predefined clusters. It is used for detecting groups of analyses within multivariate space which are not observable on bivariate plots. The optimal number of $\mathrm{k}$ can be found via applying $\mathrm{k}$-means clustering a range of $\mathrm{k}$ values to data, and assessing the sum of squared errors versus a given range of $\mathrm{k}$ ('elbow' method).

Clustering results obtained with a user-defined number of $\mathrm{k}$ are further assessed for reproducibility of clusters and overall similarity of analyses within the clusters. For considered datasets, k was chosen as three due to the high reproducibility of these clusters $>0.86$ (Supplementary Material A; Figures S1-S3). Principal component analysis significantly complements k-means as it finds the maximum variability within the data by reducing dimensionality, resulting in a linear combination of elements as principal components (PCs). Given that principal components are orthogonal, they are applicable as meaningful petrological tools, e.g., recognition of different geochemical patterns allows underpinning mineralisation/alteration and host rock signatures $[27,28]$. The PCA was performed using singular value decomposition and a biplot was used for graphical representation of the PC loadings and scores [53]. The PC scores are calculated as the linear combinations of the original variables such that the variance of the first PCs is maximal, thus the first two PCs represent the majority of variance. The PC loadings represent associations among elements therefore displaying multi-element associations within the geochemical dataset.

Finally, multiple linear regression of a response variable $\log (\mathrm{Au})$ onto ilr-coordinates of the remaining elements was fitted into each dataset using the least squares method in the ' $\operatorname{lmCoDaX}()^{\prime}$ function from the package 'robCompositions' [54]. This approach assumed that $\log (\mathrm{Au})$ is a real non-compositional response. For comparison purposes, two types of regressions were considered, classical and robust, as the latter is less affected by the presence of outliers. The purpose of regression models was to quantitatively assess the strength of relationship between $\mathrm{Au}$ and other elements.

\section{Results}

\subsection{Summary of Trace Element Signatures in Pyrite}

Although the use of standard descriptive characteristics like arithmetic mean, variance, or covariance are not appropriate for compositional data due to their scale invariance principle [55], we report the summary statistics as minimum, geometric mean, median and maximum to give an 
idea of the ranges of the concentrations within pyrite. Extended summary tables containing the above-mentioned parameters and additional arithmetic mean and standard deviation calculated for each dataset and cluster are given in Supplementary Material B. As expected, the mean/median and geometric mean increase as the number of censored values decreases in datasets.

Table 1 contains the ranges of concentrations with the corresponding geometric mean and median values for the $\mathrm{N}=1501$ dataset. Overall, the elements with the highest median concentrations and maximum values are the ones which are regularly present above mdl: Co (median $\sim 640 \mathrm{ppm}$ ), $\mathrm{Ni}$ (median $\sim 70 \mathrm{ppm}$ ) and Se (median $\sim 130 \mathrm{ppm}$ ). Their maximum values can reach up to $\sim 4.5 \mathrm{wt}$. $\%$, 0.4 wt. $\%$ and 0.1 wt. $\%$, respectively (Table 1). Although Co and Ni do not have outliers in the upper tail of their distribution (Figures $3 \mathrm{e}, 4 \mathrm{e}$ and $5 \mathrm{e}$ ), both elements have very variable concentrations, as shown by the large interquartile ranges and the presence of numerous outliers in the lower tail (Figures $3 \mathrm{e}, 4 \mathrm{e}$ and 5e). In contrast, Se varies the least among all the elements (e.g., Figure 4e). Arsenic has a median of $\sim 25 \mathrm{ppm}$ and only reaches up to $0.85 \mathrm{wt}$ \% in pyrite. Copper has a relatively low median value of $2.74 \mathrm{ppm}$, however the maximum value is three orders of magnitude higher (0.5 wt.\%). Zinc, Mn and Ti show fairly similar medians of $0.54,0.38$ and 0.43 ppm, respectively, whereas Mn has the largest maximum of $\sim 800 \mathrm{ppm}$ and a significant number of positive outliers in the upper tail (e.g., Figure 4e). Similar patterns are observed for Sn (median $0.045 \mathrm{ppm}$ ) and Ag (median $0.022 \mathrm{ppm}$ ). Gold and Re are the two elements with the lowest concentrations in pyrite. Gold is below mdl in $~ 70 \%$ of the cases (in $\mathrm{N}=4926$ data) and shows a median of only 0.005 ppm and a maximum value of $\sim 15$ ppm (Table 1). Rhenium concentrations are very low with a median of $\sim 0.01 \mathrm{ppm}$, however it is above mdl in nearly $70 \%$ of analyses.

Table 1. Summary of the trace element composition of pyrite (in ppm) for the imputed $\mathrm{N}=1501$ dataset. Elements are arranged in order of decreasing median values.

\begin{tabular}{cccccccccc}
\hline & $\mathbf{C o}$ & $\mathbf{S e}$ & $\mathbf{N i}$ & $\mathbf{A s}$ & $\mathbf{T e}$ & $\mathbf{C u}$ & $\mathbf{Z n}$ & $\mathbf{M n}$ & $\mathbf{T i}$ \\
\hline minimum & 0.28 & 4.0 & 0.015 & 0.35 & 0.009 & 0.096 & 0.12 & 0.060 & 0.049 \\
maximum & 44267 & 1075 & 4357 & 8586 & 815 & 5467 & 167 & 809 & 56 \\
$\begin{array}{c}\text { median } \\
\text { geom. }\end{array}$ & 643 & 133 & 69 & 25 & 4.89 & 2.74 & 0.54 & 0.38 & 0.43 \\
mean & 586 & 121 & 48 & 26 & 4.06 & 3.68 & 0.62 & 0.58 & 0.48 \\
\hline & $\mathbf{2 0 6} \mathbf{P b}$ & $\mathbf{2 0 4} \mathbf{P b}$ & $\mathbf{2 0 7} \mathbf{P b}$ & $\mathbf{2 0 8} \mathbf{P b}$ & $\mathbf{B i}$ & $\mathbf{S n}$ & $\mathbf{A g}$ & $\mathbf{R e}$ & $\mathbf{A u}$ \\
\hline $\begin{array}{c}\text { minimum } \\
\text { maximum }\end{array}$ & 0.001 & 0.043 & 0.001 & 0.0008 & 0.0003 & 0.017 & 0.001 & 0.0004 & 0.0003 \\
$\begin{array}{c}\text { median } \\
\text { geom. }\end{array}$ & 0.29 & 0.23 & 0.12 & 0.10 & 0.12 & 0.045 & 0.022 & 0.014 & 0.005 \\
mean & 0.40 & 0.36 & 0.16 & 0.14 & 0.12 & 0.064 & 0.037 & 0.011 & 0.008 \\
\hline
\end{tabular}

Note: geom. mean-geometric mean.

\subsection{Principal Component Analysis, K-Means Clustering and Dendrogram}

The results of statistical analyses obtained from the $\mathrm{N}=4926$ dataset (Figure 3 ) are slightly different to those from both the $\mathrm{N}=1501$ (Figure 4) and $\mathrm{N}=525$ (Figure 5) datasets which demonstrate more similarities with respect to the groupings of elements on their PCA loadings and respective dendrograms. The obtained dendrograms from the trimmed data highlight a group of $\mathrm{Ag}-\mathrm{Bi}-\mathrm{Pb}-\mathrm{Au}-\mathrm{Cu}$ (Figures 4 and $5 \mathrm{~d}$ ). Despite the presence of many left-censored values within the $\mathrm{N}=4926$ dataset, the PC1 in all three datasets are dominated by the $\mathrm{Bi}-{ }^{X} \mathrm{~Pb}-\mathrm{Ag}$ signature, thus being the predominant feature of Olympic Dam pyrite.

However, as the trimmed datasets have fewer left-censored values, the groups on dendrograms and association of elements loading onto PC1 slightly change. In the N = 1501 and N = 525 datasets, the PC1 is dominated by all four $\mathrm{Pb}$ isotopes with $\mathrm{Ag}, \mathrm{Bi}, \mathrm{Cu}$ and minor $\mathrm{Au}$ loadings (Figure $4 \mathrm{a}$, $\mathrm{d}$ and Figure 5a,d). In contrast, in the $\mathrm{N}=4926$ data, Bi is associated with ${ }^{206} \mathrm{~Pb},{ }^{207} \mathrm{~Pb}$ and ${ }^{208} \mathrm{~Pb}$ while ${ }^{204} \mathrm{~Pb}$ plots separately (Figure 3a,d). 

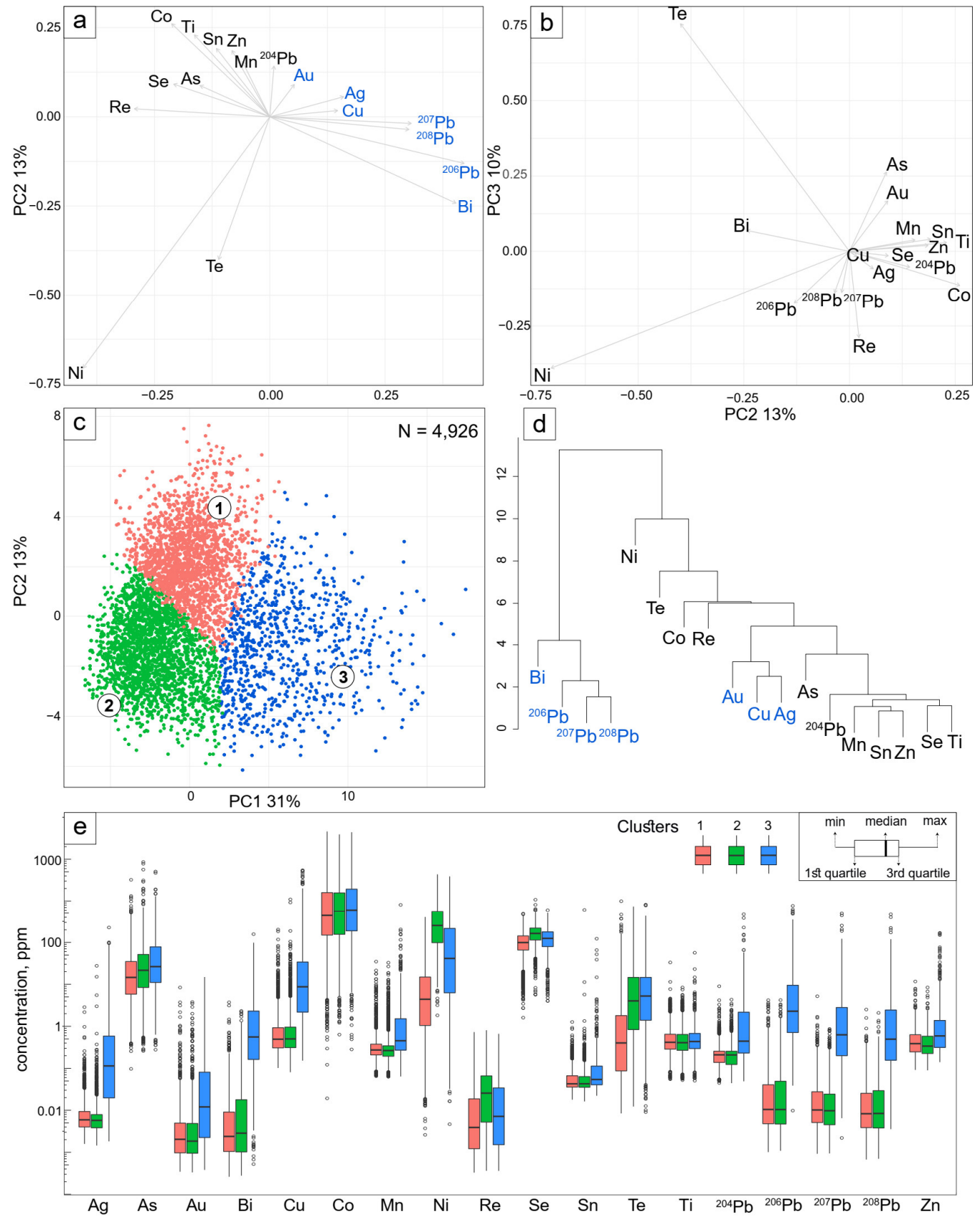

Figure 3. Principal component scores and loadings of centred log-ratio-transformed $N=4926$ data. The projection of PC1 versus PC2 (a) and PC2 versus PC3 (b) shows loadings of the elements. Principal component scores are shown on the PC1 versus PC2 projection (c), on which each dot corresponds to an individual sample assigned to one of three clusters. Hierarchical cluster dendrogram (d) showing the association among the 18 elements with the height being a dissimilarity measure calculated from the variation matrix using Euclidean metrics (Table 2). (e) Box and whisker plot showing a range of concentrations for elements within each cluster. Note the correspondence among Cluster 3 and the $\mathrm{Pb}$ isotopes and $\mathrm{Bi}$. 

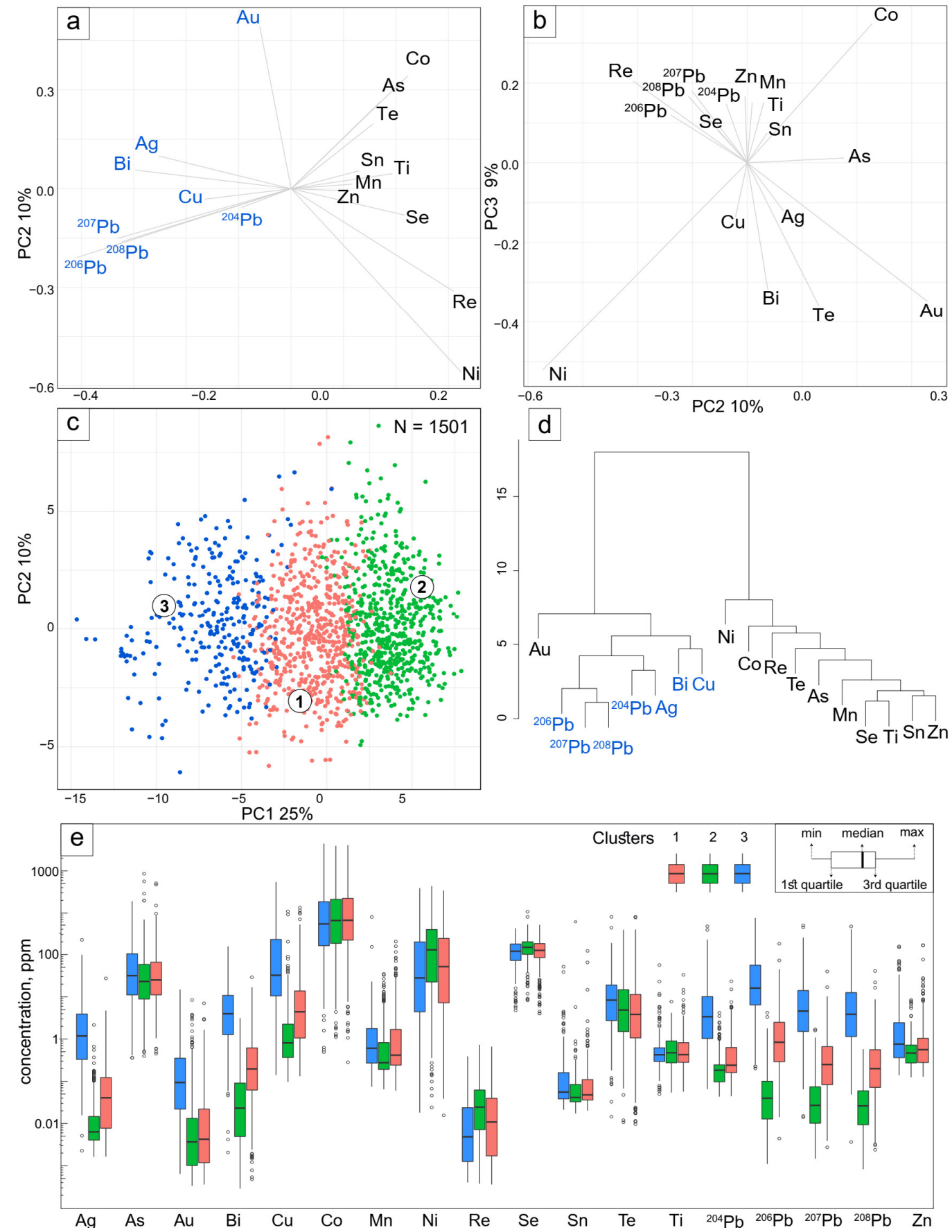

Figure 4. Principal component scores and loadings of centred log-ratio-transformed N = 1501 data. The projection of PC1 versus PC2 (a) and PC2 versus PC3 (b) shows loadings of the elements. Principal component scores are shown on the PC1 versus PC2 projection (c), on which each dot corresponds to an individual sample assigned to one of three clusters. Hierarchical cluster dendrogram (d) showing the association among the 18 elements with the height being a dissimilarity measure calculated from the variation matrix using Euclidean metrics (Table 3). (e) Box and whisker plot showing a range of concentrations for elements within each cluster. Note the correspondence among Cluster 3 and the $\mathrm{Pb}$ isotopes and $\mathrm{Bi}$.

Another shared feature across the trimmed versions of the data is $\mathrm{Ni}$, showing the highest disproportionality, i.e., least correlation with $\mathrm{Bi}, \mathrm{Ag}$, $\mathrm{Au}$ and $\mathrm{Cu}$ (e.g., $\tau_{\mathrm{NiBi}}=11.5 ; \tau_{\mathrm{NiAg}}=10.6$; $\tau_{\mathrm{NiAu}}=9.9$; Table 3), as well as ${ }^{206} \mathrm{~Pb},{ }^{207} \mathrm{~Pb}$ and ${ }^{208} \mathrm{~Pb}$. Cobalt is also always uncorrelated with Bi (e.g., 
$\tau_{C o B i}=10.0$; Table 3). Additional patterns are shown in trimmed data $(\mathrm{N}=1501$ and $\mathrm{N}=525)$, where $\mathrm{Co}, \mathrm{Ni}$ as well as Re show negative association with ${ }^{206} \mathrm{~Pb},{ }^{207} \mathrm{~Pb}$ and ${ }^{208} \mathrm{~Pb}$ and $\mathrm{Ag}$. Such dissociation demonstrates Ni-Co being another dominant feature of Olympic Dam pyrite, as both are having the highest loadings onto $\mathrm{PC} 1$, thus opposing the $\mathrm{Ag}-\mathrm{Bi}-{ }^{\mathrm{X}} \mathrm{Pb}-\mathrm{Cu}-\mathrm{Au}$ group.

Although displaying less information than PC1, the PC2-PC3 projection represents a total of $18 \%$ of the data variability and shows different geochemical associations which are valid although not captured by the dendrograms or variation matrices. The dominant characteristic of PC2-PC3 projection is the dissociation between $\mathrm{Ni}$ and $\mathrm{Co}$, which plot on the opposite sites of the loading plot in the original and all trimmed datasets (Figures $3 b, 4 b$ and $5 b$ ). Given that both elements are constantly present above their respective detection limits, it may be concluded that such $\mathrm{Ni}-\mathrm{Co}$ dissociation reflects characteristic pyrite signatures, i.e., zonation patterns that are characterised by either intra-grain oscillatory zoning at a scale larger that the spot size used for LA-ICP-MS analysis, or selective (re)mobilisation of Co relative to $\mathrm{Ni}$.

Two other important associations of the PC2-PC3 projection include the four $\mathrm{Pb}$ isotopes, ${ }^{204} \mathrm{~Pb}$, ${ }^{206} \mathrm{~Pb},{ }^{207} \mathrm{~Pb}$ and ${ }^{208} \mathrm{~Pb}$, which group together with Re and Se. Whereas the ${ }^{\mathrm{X}} \mathrm{Pb}-\mathrm{Re}-\mathrm{Se}$ association typifies a molybdenite-Pb-chalcogenide signature, $\mathrm{Co}$ and As are likely to occur in the pyrite crystal lattice. Interestingly, As is not associated with $\mathrm{Au}$ in PC1-PC2; there is, however, a slight correlation in the PC2-PC3 projection.

The most highly correlated $\tau_{i j}$ values correspond to, as expected, the Pb isotopes (Tables 2-4). In the untrimmed data, ${ }^{204} \mathrm{~Pb}$ shows the higher proportionality with $\mathrm{Sn}\left(\tau_{204 \mathrm{PbSn}}=1.4\right)$ and $\mathrm{Ag}$ $\left(\tau_{204 P b A g}=1.8\right)$ compared to the other Pb isotopes. However, the relationships among Pb isotopes change markedly in the trimmed data, where all four $\mathrm{X}_{\mathrm{Pb}}$ become strongly correlated. In the original data, there is a very strong proportionality between Ti-Se, Ti-Sn and Sn-Mn $\left(\tau_{\text {TiSe }}=1.1, \tau_{\text {TiSn }}=1.1\right.$, $\tau_{S n M n}=1.1$; Table 2) which is likely to be real as such a relationship is preserved in the trimmed data (Tables 3 and 4). Other consistently high correlations are attributed to Se which shows relationships with As and also with $\operatorname{Re}\left(\tau_{\text {SeAs }}=2.8 ; \tau_{\text {SeRe }}=2.7\right.$; Table 3$)$ and Co which shows the highest correlation with Se and As (e.g., $\tau_{C o S e}=4.2 ; \tau_{C o A s}=4.1$; Table 3). In all the data, Au shows more correlation with Ag than with As (e.g., $\tau_{A u A g}=4.6 ; \tau_{A u A s}=5.6$ in Table 3; Tables 2-4).

Table 2. Variation matrix for the $\mathrm{N}=4926$ dataset with entries as the variances of log-ratios for each element pair. The underscored values indicate the weakest column-wise co-dependence.

\begin{tabular}{|c|c|c|c|c|c|c|c|c|c|c|c|c|c|c|c|c|c|}
\hline & $\mathrm{Au}$ & $\mathbf{B i}$ & $\mathrm{Cu}$ & Co & Mn & $\mathbf{N i}$ & $\operatorname{Re}$ & Se & Sn & $\mathrm{Te}$ & $\mathbf{T i}$ & ${ }^{204} \mathrm{~Pb}$ & ${ }^{206} \mathrm{~Pb}$ & ${ }^{207} \mathrm{~Pb}$ & ${ }^{208} \mathrm{~Pb}$ & $\mathrm{Zn}$ & $\mathrm{Ag}$ \\
\hline As & 4.1 & 7.4 & 4.6 & 4.4 & 3.0 & 7.6 & 5.9 & 2.6 & 2.7 & 5.3 & 2.8 & 3.1 & 7.4 & 5.7 & 5.8 & 2.7 & 4.5 \\
\hline $\mathbf{A u}$ & & 5.2 & 3.4 & 5.7 & 2.7 & $\underline{9.0}$ & 6.1 & 3.4 & 2.6 & 5.7 & 3.1 & 2.3 & 5.4 & 3.9 & 4.0 & 2.6 & 2.6 \\
\hline $\mathbf{B i}$ & & & 4.1 & 9.6 & 5.6 & $\overline{12.3}$ & 10.1 & 7.4 & 6.4 & 8.0 & 7.4 & 5.3 & 3.5 & 3.7 & 3.7 & 6.1 & 4.1 \\
\hline $\mathrm{Cu}$ & & & & $\overline{6.2}$ & 2.8 & 9.1 & $\overline{6.2}$ & 3.5 & 2.8 & 6.3 & 3.6 & 2.6 & 3.9 & 3.0 & 3.0 & 2.7 & 2.5 \\
\hline Co & & & & & 4.3 & $\overline{8.7}$ & 6.4 & 4.1 & 4.1 & 8.4 & 4.1 & 4.5 & $\underline{9.2}$ & 7.2 & 7.3 & 4.2 & 5.8 \\
\hline Mn & & & & & & 7.4 & 4.0 & 1.4 & 1.1 & 5.1 & 1.3 & 1.5 & 5.2 & 3.5 & 3.5 & 0.9 & 2.8 \\
\hline $\mathrm{Ni}$ & & & & & & & 6.9 & 5.6 & 7.1 & 8.4 & 7.2 & 7.5 & $\underline{12.2}$ & $\underline{10.6}$ & 10.4 & 7.3 & $\underline{9.0}$ \\
\hline $\operatorname{Re}$ & & & & & & & & 2.8 & 3.6 & 7.5 & 3.8 & 4.2 & $\overline{9.4}$ & $\overline{7.5}$ & $\overline{7.4}$ & 3.8 & $\overline{6.1}$ \\
\hline Se & & & & & & & & & 1.0 & 4.9 & 1.1 & 1.7 & 6.7 & 4.8 & 4.8 & 1.2 & 3.3 \\
\hline Sn & & & & & & & & & & 5.1 & 1.1 & 1.4 & 5.8 & 4.1 & 4.1 & 0.9 & 2.8 \\
\hline Te & & & & & & & & & & & 5.7 & 5.5 & 8.6 & 7.3 & 7.2 & 5.2 & 6.4 \\
\hline $\mathrm{Ti}$ & & & & & & & & & & & & 1.7 & 6.7 & 4.8 & 4.8 & 1.2 & 3.3 \\
\hline${ }^{204} \mathrm{~Pb}$ & & & & & & & & & & & & & 4.3 & 2.6 & 2.7 & 1.1 & 1.8 \\
\hline${ }^{206} \mathrm{~Pb}$ & & & & & & & & & & & & & & 2.1 & 2.2 & 5.4 & 3.5 \\
\hline${ }^{207} \mathrm{~Pb}$ & & & & & & & & & & & & & & & 1.5 & 3.6 & 2.5 \\
\hline${ }^{208} \mathrm{~Pb}$ & & & & & & & & & & & & & & & & 3.6 & 2.6 \\
\hline $\mathrm{Zn}$ & & & & & & & & & & & & & & & & & 2.6 \\
\hline
\end{tabular}


Table 3. Variation matrix for the $\mathrm{N}=1501$ dataset with entries as the variances of log-ratios for each element pair. The underscored values indicate the weakest column-wise co-dependence.

\begin{tabular}{|c|c|c|c|c|c|c|c|c|c|c|c|c|c|c|c|c|c|}
\hline & $\mathbf{A u}$ & $\mathbf{B i}$ & $\mathrm{Cu}$ & Co & Mn & $\mathrm{Ni}$ & $\operatorname{Re}$ & Se & Sn & $\mathrm{Te}$ & $\mathrm{Ti}$ & ${ }^{204} \mathrm{~Pb}$ & ${ }^{206} \mathrm{~Pb}$ & ${ }^{207} \mathrm{~Pb}$ & ${ }^{208} \mathrm{~Pb}$ & $\mathrm{Zn}$ & $\mathrm{Ag}$ \\
\hline As & 5.6 & 7.5 & 6.5 & 4.1 & 4.1 & 6.9 & 5.9 & 2.8 & 3.1 & 4.0 & 3.0 & 4.3 & 8.7 & 7.2 & 7.1 & 3.3 & 6.7 \\
\hline $\mathrm{Au}$ & & 6.0 & 6.1 & 7.4 & 5.7 & $\underline{9.9}$ & 8.8 & 5.5 & 4.6 & 5.3 & 5.2 & 4.3 & 7.6 & 6.1 & 6.2 & 4.8 & 4.6 \\
\hline $\mathbf{B i}$ & & & 4.7 & $\underline{10.0}$ & 6.5 & $\overline{11.5}$ & $\underline{10.8}$ & 7.5 & 6.4 & 7.4 & 7.6 & 4.6 & 4.3 & 4.1 & 3.9 & 6.3 & 4.3 \\
\hline $\mathrm{Cu}$ & & & & $\overline{8.6}$ & 5.5 & $\overline{9.8}$ & $\overline{8.7}$ & 5.5 & 4.4 & 6.8 & 5.7 & 4.2 & 5.1 & 4.6 & 4.7 & 4.6 & 4.5 \\
\hline Co & & & & & 5.4 & $\overline{8.4}$ & 6.5 & 4.2 & 4.8 & 6.7 & 4.4 & 5.8 & 10.8 & 8.9 & 8.9 & 5.0 & 8.3 \\
\hline Mn & & & & & & 7.0 & 5.0 & 2.4 & 2.4 & 4.2 & 2.5 & 3.5 & $\overline{7.6}$ & 5.8 & 5.6 & 1.8 & 6.6 \\
\hline $\mathrm{Ni}$ & & & & & & & 6.3 & 4.5 & 6.1 & 6.8 & 5.9 & 7.7 & $\underline{12.9}$ & $\underline{11.3}$ & $\underline{11.1}$ & 6.4 & $\underline{10.6}$ \\
\hline $\operatorname{Re}$ & & & & & & & & 2.7 & 4.2 & 6.3 & 3.9 & 5.8 & $\overline{11.6}$ & $\overline{9.7}$ & 9.6 & 4.4 & $\overline{9.3}$ \\
\hline Se & & & & & & & & & 1.5 & 3.5 & 1.2 & 3.0 & $\overline{8.2}$ & $\overline{6.4}$ & $\overline{6.3}$ & 1.6 & $\overline{5.9}$ \\
\hline Sn & & & & & & & & & & 3.8 & 1.6 & 2.8 & 7.2 & 5.6 & 5.5 & 1.5 & 5.6 \\
\hline $\mathrm{Te}$ & & & & & & & & & & & 4.2 & 5.0 & 9.3 & 7.8 & 7.6 & 4.0 & 7.3 \\
\hline $\mathrm{Ti}$ & & & & & & & & & & & & 3.1 & $\overline{8.3}$ & 6.5 & 6.5 & 1.9 & 6.2 \\
\hline${ }^{204} \mathrm{~Pb}$ & & & & & & & & & & & & & 3.9 & 2.4 & 2.4 & 2.2 & 3.3 \\
\hline${ }^{206} \mathrm{~Pb}$ & & & & & & & & & & & & & & 1.8 & 1.9 & 6.5 & 4.0 \\
\hline${ }^{207} \mathrm{~Pb}$ & & & & & & & & & & & & & & & 1.1 & 4.8 & 3.4 \\
\hline${ }^{208} \mathrm{~Pb}$ & & & & & & & & & & & & & & & & 4.7 & 3.5 \\
\hline $\mathrm{Zn}$ & & & & & & & & & & & & & & & & & 5.3 \\
\hline
\end{tabular}

Table 4. Variation matrix for the $\mathrm{N}=525$ dataset with entries as the variances of log-ratios for each element pair. The underscored values indicate the weakest column-wise co-dependence.

\begin{tabular}{|c|c|c|c|c|c|c|c|c|c|c|c|c|c|c|c|c|c|}
\hline & $\mathrm{Au}$ & $\mathbf{B i}$ & $\mathrm{Cu}$ & Co & Mn & $\mathrm{Ni}$ & $\operatorname{Re}$ & $\mathrm{Se}$ & Sn & $\mathrm{Te}$ & $\mathrm{Ti}$ & ${ }^{204} \mathrm{~Pb}$ & ${ }^{206} \mathrm{~Pb}$ & ${ }^{207} \mathrm{~Pb}$ & ${ }^{208} \mathrm{~Pb}$ & $\mathrm{Zn}$ & $\mathrm{Ag}$ \\
\hline As & 5.9 & 7.0 & 7.4 & 3.8 & 4.2 & 6.3 & 5.7 & 2.6 & 4.0 & 3.4 & 3.1 & 5.7 & 8.4 & 7.0 & 7.1 & 4.1 & 7.8 \\
\hline $\mathrm{Au}$ & & 4.8 & 6.3 & 8.2 & 6.8 & 9.6 & 9.5 & 5.7 & 5.3 & 5.0 & 5.4 & 5.1 & 6.7 & 5.7 & 5.8 & 5.4 & 4.8 \\
\hline $\mathbf{B i}$ & & & 4.7 & $\underline{9.6}$ & 6.9 & $\overline{9.9}$ & $\overline{9.5}$ & 6.1 & 5.9 & 6.3 & 6.2 & 3.7 & 4.2 & 3.4 & 3.5 & 5.5 & 3.9 \\
\hline $\mathrm{Cu}$ & & & & $\overline{\mathbf{1 0 . 1}}$ & 6.7 & $\overline{9.4}$ & $\overline{9.3}$ & 5.5 & 5.0 & 6.6 & 5.8 & 5.2 & 5.6 & 5.2 & 5.4 & 4.8 & 5.7 \\
\hline Co & & & & & 5.7 & $\overline{8.0}$ & $\overline{6.3}$ & 4.3 & 6.4 & 6.0 & 4.6 & 7.4 & 10.9 & 9.2 & 9.3 & 6.0 & 9.9 \\
\hline Mn & & & & & & 6.7 & 5.7 & 2.6 & 3.4 & 3.5 & 2.8 & 5.5 & $\overline{8.4}$ & $\overline{6.7}$ & $\overline{6.8}$ & 2.4 & $\overline{8.8}$ \\
\hline $\mathrm{Ni}$ & & & & & & & 5.8 & 4.1 & 6.2 & 6.0 & 5.1 & 8.7 & 12.1 & 10.2 & 10.3 & 6.4 & 11.0 \\
\hline $\operatorname{Re}$ & & & & & & & & 2.8 & 5.6 & 5.5 & 4.0 & 7.6 & $\overline{\mathbf{1 1 . 2}}$ & $\overline{9.5}$ & $\overline{9.5}$ & 5.2 & $\overline{\mathbf{1 0 . 6}}$ \\
\hline Se & & & & & & & & & 2.3 & 2.6 & 1.3 & 4.3 & $\overline{7.2}$ & $\overline{5.8}$ & $\overline{5.8}$ & 2.1 & $\overline{6.7}$ \\
\hline Sn & & & & & & & & & & 3.5 & 2.2 & 4.9 & 7.5 & 6.0 & 6.1 & 2.3 & 7.5 \\
\hline $\mathrm{Te}$ & & & & & & & & & & & 3.2 & 5.6 & 8.4 & 7.0 & 7.0 & 3.7 & 7.6 \\
\hline $\mathrm{Ti}$ & & & & & & & & & & & & 4.6 & 7.5 & 6.0 & 6.1 & 2.5 & 7.0 \\
\hline${ }^{204} \mathrm{~Pb}$ & & & & & & & & & & & & & 2.4 & 1.1 & 1.1 & 3.5 & 3.6 \\
\hline${ }^{204} \mathrm{~Pb}$ & & & & & & & & & & & & & & 0.9 & 1.2 & 5.9 & 3.7 \\
\hline${ }^{204} \mathrm{~Pb}$ & & & & & & & & & & & & & & & 0.4 & 4.5 & 3.4 \\
\hline${ }^{204} \mathrm{~Pb}$ & & & & & & & & & & & & & & & & 4.4 & 3.4 \\
\hline $\mathrm{Zn}$ & & & & & & & & & & & & & & & & & 6.4 \\
\hline
\end{tabular}



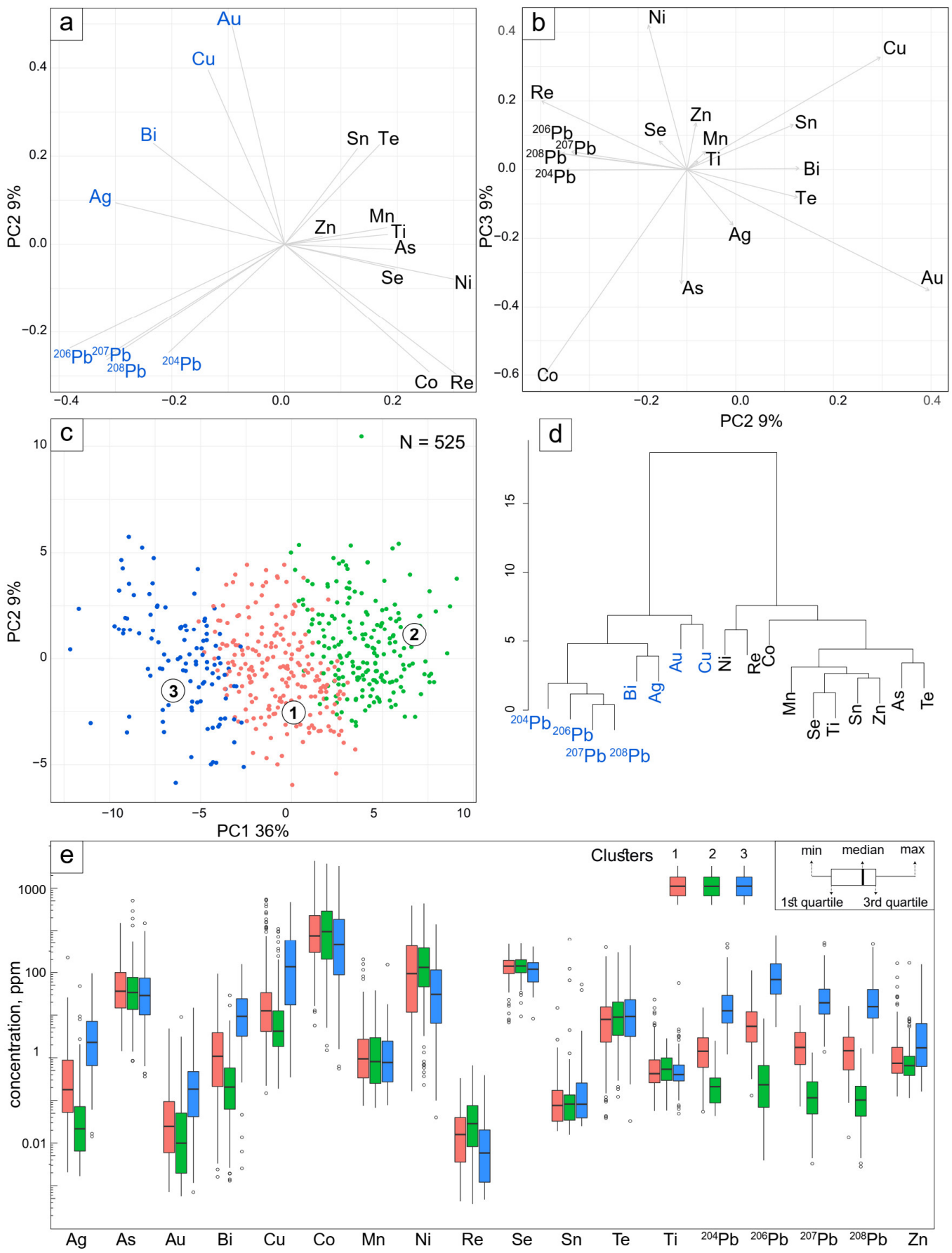

Figure 5. Principal component scores and loadings of centred log-ratio-transformed $N=525$ data. The projection of PC1 versus PC2 (a) and PC2 versus PC3 (b) shows loadings of the elements. Principal component scores are shown on the PC1 versus PC2 projection (c), on which each dot corresponds to an individual sample assigned to one of three clusters (Supplementary Material B). Hierarchical cluster dendrogram (d) showing the association among the 18 elements with the height being a dissimilarity measure calculated from the variation matrix using Euclidean metrics (Table 4). (e) Box and whisker plot showing a range of concentrations for elements within each cluster. Note the correspondence among Cluster 3 and the $\mathrm{Pb}$ isotopes and $\mathrm{Bi}$.

The k-means clustering was performed for each dataset individually using the dendrogram knots to derive ilr-coordinates. Because of that, the clusters are not directly comparable across three datasets, although the Cluster 3 dominated by $\mathrm{Ag}-\mathrm{Bi}-{ }^{X} \mathrm{~Pb}$ signature, is the only one that is consistently present 
across all the data despite the left-censored values (Figure $3 c, e$, Figure $4 c$,e and Figure $5 c, e$ ). The results of k-mean clustering obtained from trimmed data $(\mathrm{N}=1501$ and $\mathrm{N}=525)$ are similar to each other and slightly differ from the original data $(\mathrm{N}=4926)$ (Supplementary Material B; Tables S4-S6). Within the original data, Clusters 1 and 2 are distinguished by $\mathrm{Ni}$ concentrations, whereas $\mathrm{Ni}$ is significantly enriched in Cluster 2 (median $=252$ ppm; Supplementary Material B; Table S4) than in Cluster 1 (median $=4.4 \mathrm{ppm}$ ). Given that both $\mathrm{Ni}$ and $\mathrm{Co}$ are measured above mdl, the clustering strongly supports their different distribution in the analysed pyrite. The inverse positioning of $\mathrm{Ni}$ and $\mathrm{Co}$ on $\mathrm{PC} 2-\mathrm{PC} 3$ projection also confirms a wide range of $\mathrm{Co} / \mathrm{Ni}$ ratios present within the data (e.g., $\mathrm{Co} / \mathrm{Ni}$ ratio medians: Cluster 1-100; Cluster 2-2; Cluster 3-14; Supplementary Material B).

The results of k-means clustering of the trimmed datasets are, however, less interpretable. In both cases, the geochemical clusters are defined by the concentrations of $\mathrm{Ag}-\mathrm{Bi}-{ }_{\mathrm{Pb}}-\mathrm{Cu}$ with Cluster 3 being the highest and Clusters 1 and 2 having consequently smaller values of these elements. Similarly, there is no obvious distinction among Clusters 1 and 2 in the trimmed data apart from the decrease in the concentration of $\mathrm{Ag}-\mathrm{Bi}-{ }^{X} \mathrm{~Pb}-\mathrm{Cu}$ with Cluster 2 having the lowest values (Figures 4 and $5 \mathrm{e}$ ).

\subsection{Multiple Linear Regression}

Table 5 shows the result of robust multiple linear regression of $\log (\mathrm{Au})$ onto the ilr-coordinates of seventeen elements in the form of the output of $R$ routine linear model. The columns correspond to the estimated regression parameters (Estimate), their standard errors (Std. Error), t statistics obtained as parameter estimates divided by their standard errors ( $t$ value) and the $p$-values $(\operatorname{Pr}(>|t|))$. The complete results of classic and robust regressions fitted into each of the datasets are given in Supplementary Material C. All fitted models were significant; however, they demonstrate adjusted R-squared values from 0.3 to 0.5 , which is in accordance with highly variable data obtained via random spot analysis of pyrite grains.

Table 5. Results from robust multiple regression of the $\log (\mathrm{Au})$ for the ilr-coordinates of the remaining 17 elements in $\mathrm{N}=1501$ dataset. The extended results of classic and robust regressions fitted to the three datasets are in Supplementary Material C.

\begin{tabular}{|c|c|c|c|c|c|c|c|c|c|}
\hline & Intercept & Se & Ag & ${ }^{204} \mathrm{~Pb}$ & $\mathrm{Te}$ & $\overline{\mathrm{Bi}}$ & ${ }^{206} \mathrm{~Pb}$ & Mn & Co \\
\hline Estimate & 0.11 & -0.33 & 0.18 & 0.10 & 0.07 & 0.05 & -0.05 & -0.03 & -0.02 \\
\hline Std. Error & 0.17 & 0.02 & 0.01 & 0.02 & 0.01 & 0.01 & 0.01 & 0.01 & 0.01 \\
\hline $\mathrm{t}$ value & 0.67 & -13.55 & 14.63 & 5.52 & 6.61 & 4.12 & -3.07 & -2.18 & -2.01 \\
\hline $\operatorname{Pr}(>|t|)$ & 0.505 & 0.000 & 0.000 & 0.000 & 0.000 & 0.000 & 0.002 & 0.030 & 0.045 \\
\hline \multirow[t]{2}{*}{ significance } & & $* * *$ & $* * *$ & $* * *$ & $* * *$ & $* * *$ & ** & $*$ & * \\
\hline & $\mathrm{Cu}$ & $\mathrm{Ni}$ & As & Sn & $\operatorname{Re}$ & ${ }^{208} \mathrm{~Pb}$ & ${ }^{207} \mathrm{~Pb}$ & Zn & Ti \\
\hline Estimate & -0.02 & 0.01 & 0.01 & 0.01 & 0.00 & -0.01 & 0.00 & 0.00 & 0.00 \\
\hline Std. Error & 0.01 & 0.01 & 0.01 & 0.02 & 0.01 & 0.02 & 0.02 & 0.02 & 0.02 \\
\hline $\mathrm{t}$ value & -1.57 & 0.75 & 0.71 & 0.36 & -0.36 & -0.28 & 0.15 & 0.04 & 0.11 \\
\hline $\operatorname{Pr}(>|t|)$ & 0.117 & 0.451 & 0.481 & 0.719 & 0.719 & 0.777 & 0.879 & 0.968 & 0.911 \\
\hline significance & - & - & - & - & - & - & - & - & - \\
\hline
\end{tabular}

Throughout the original and trimmed datasets, Ag is consistently the best predictor for Au with the largest positive coefficient and $t$ statistics (Table 5), suggesting that an increase in the Ag concentration within pyrite is always associated with increase in that of Au. Selenium is also a significant predictor of $\mathrm{Au}$, however, in this case the coefficients are negative (e.g., estimate -0.33 ; Table 5 ), inferring an inverse relationship between Se and $\mathrm{Au}$. Overall, $\mathrm{Ag}$, $\mathrm{Te}$ and $\mathrm{Bi}$ are three elements that are good predictors of $\mathrm{Au}$. Interestingly, ${ }^{204} \mathrm{~Pb}$ and ${ }^{206} \mathrm{~Pb}$ were assigned as significant predictors for $\mathrm{Au}$ in the $\mathrm{N}=4926$ and $\mathrm{N}=1501$ datasets, although ${ }^{204} \mathrm{~Pb}$ exhibited a positive, and ${ }^{206} \mathrm{~Pb}$ having a negative coefficient. However, none of the $\mathrm{Pb}$ isotopes were significant for Au prediction in the smaller $(\mathrm{N}=525)$ dataset. 
Arsenic and $\mathrm{Ni}$ are not important for Au prediction, whereas $\mathrm{Co}$ appears to be slightly significant with a negative coefficient in a few models (e.g., Table 5).

\section{Discussion}

\subsection{Trace Element Signature of Pyrite: Prediction and Bias for Complex Sulphide Ores}

As part of complex sulphide ore assemblages at Olympic Dam, pyrite is characterised by the presence of several trace elements of current or potential economic and/or metallurgical importance. Despite the intricate, grain-scale intergrowths between pyrite with chalcopyrite, three elements, As, $\mathrm{Co}$, and Se, well known to be bound within the pyrite lattice at concentrations up to wt.\% levels, give generally flat signals on the time-resolved LA-ICP-MS downhole profiles and have nearly overlapping mean and median values and are therefore not discriminative of any cluster (Supplementary Material B). The three elements, and to a lesser extent, also Te, are commonly present in pyrite from a variety of hydrothermal environments [56], including in IOCG deposits, as shown here for Olympic Dam, or known from Ernest Henry [34]. The two associations, $\mathrm{Au}-\mathrm{Co}-\mathrm{As}$ and $\mathrm{Ag}-\mathrm{Au}$, depicted by PC2 show element groups that could be lattice-bound but, intriguingly, may equally occur as fine particles and/or $\mathrm{NPs}$. Indeed, Au-Ag-NPs have been reported from arsenic-free pyrite elsewhere and may be more common than presently known [24].

Pyrite is clearly an important host for Co at Olympic Dam. An understanding of the deportment of $\mathrm{Co}$, an element recognised as characteristically enriched in IOCG systems relative to other magmatic-hydrothermal ore types [57], is important as this element represents both a potential target for future recovery but also because Co concentrations within copper concentrates need to be kept within acceptable limits. Even though carrollite and cobaltite inclusions in pyrite are known at Olympic Dam [33], the lack of significant large outliers in the Co concentration data for pyrite, together with the relatively stable Co signal on the LA-ICP-MS depth profiles strongly supports that it is exclusively lattice-bound. The variation in Co signal intensity observed in some depth profiles is readily attributed to the marked grain-scale zoning with respect to this element.

The same applies to $\mathrm{Ni}$, although at concentrations which are appreciable lower. Interestingly, among all elements, $\mathrm{Ni}$ shows the greatest disproportionality, i.e., the least correlation with $\mathrm{Bi}, \mathrm{Ag}, \mathrm{Au}$ and $\mathrm{Cu}$-inferring that $\mathrm{Ni}$-rich bands are relatively depleted in these elements. The low $\mathrm{Ni}$ content gives a typical $\mathrm{Co} / \mathrm{Ni}$ ratio of around 10. One interpretation of the very high $\mathrm{Co} / \mathrm{Ni}$ ratio in Cluster 1 (median 100; Supplementary Material B; Table S4), would be that pyrite assigned to this cluster contains individual Co-bearing mineral inclusions. Alternatively, and our preferred interpretation, is to attribute this to independent zoning patterns at the grain-scale, an argument also supported by their limited association (Figures $3 \mathrm{~b}, 4 \mathrm{~b}$ and $5 \mathrm{~b}$ ). It should be noted that the overall lack of correlation between $\mathrm{Co}$ and $\mathrm{Ni}$ at the scale of single mineral grain contrasts markedly with whole-rock data from Olympic Dam, in which Ni and Co correlate spatially, and together define the pyrite-chalcopyrite zone (in which the greater part of the pyrite occurs; [33]). Comparably wide ranges of $\mathrm{Co} / \mathrm{Ni}$ are described from other IOCG and related systems [36,58].

The remarkably constant concentrations of Se (typically 100-150 ppm; Supplementary Material B) are taken as indicating a lack of grain-scale zoning and homogenisation during any recrystallisation. Although reasonably homogenous across the clusters, As concentrations in pyrite, albeit at generally low absolute concentrations, show subtle variation suggesting grain-scale zoning, at least at the scale of the LA-ICP-MS spot analysis. Sub-micron scale compositional zoning is also most likely present within the analysed pyrite. There is a correlation between As and $\mathrm{Co}(-\mathrm{Ni})$ grains; although grain-scale zoning may not be coincident, those grains which are zoned with respect to one element are typically also zoned with respect to the other.

Despite the low average concentrations, $\sim 25 \mathrm{ppm}$ As (median of the $\mathrm{N}=1501$ dataset) in Olympic Dam pyrite, it is potentially the second largest host for As in the deposit after hematite [44], considering its proportion in the ore. The data presented here show that although pyrite contains measurable 
gold, average contents are negligible, thus inferring that Olympic Dam pyrite is not 'arsenian' and that invisible gold in pyrite is not commonplace within the deposit. This is concordant with the well-documented occurrence of gold as native gold, electrum and less commonly, Au-Ag-tellurides throughout the deposit [33]. Invisible gold defined by the 'Au incorporation via As' paradigm cannot, however, be dismissed since the data show that a minority of pyrite grains analysed do contain $\mathrm{Au}$ - at noteworthy concentrations of maximum of $14 \mathrm{ppm}$ (at the scale of the LA-ICP-MS crater) and furthermore that such pyrite is As-bearing. However, this type of 'invisible' gold is represented by a small proportion of $\mathrm{Au}$ since As is not a significant predictor for Au concentrations (Table 5; Supplementary Material C). The loading of $\mathrm{Au}$ in all three plots of PC1s plots perpendicular to As and to $\mathrm{Bi}-\mathrm{Ag}-\mathrm{Pb}$, suggesting that $\mathrm{PC} 1$ predicts other possible host phases for $\mathrm{Au}$, tellurides and electrum as nanoparticles/'invisible' Au.

A key characteristic of Olympic Dam pyrite is thus the prediction of tellurides of $\mathrm{Ag}-\mathrm{Au}, \mathrm{Bi}-\mathrm{Pb}$, $\mathrm{Ag}-\mathrm{Bi}$ and $\mathrm{Pb}$. Tellurium is distributed nearly equally across all the defined pyrite clusters (Figures $3 \mathrm{e}$, $4 \mathrm{e}$ and $5 \mathrm{e}$; Supplementary Material $\mathrm{B})$, and never plots together with the $\mathrm{Ag}-\mathrm{Bi}-\mathrm{Pb}-(\mathrm{Au})$ signature. We can infer that Te occurs within the pyrite lattice, presumably at low concentration levels but forms telluride phases where present at higher concentrations. Despite the fact that $\mathrm{Te}$ is assigned to a distinct group from $\mathrm{Ag}-\mathrm{B}-\mathrm{Pb}-(\mathrm{Au})$ association, it might be concluded that $\mathrm{Te}$ forms $\mathrm{Bi}-\mathrm{Ag}-\mathrm{Pb}-(\mathrm{Au})$ telluride phases. The latter is also supported by Te being one of the most significant predictors of $\mathrm{Au}$ concentrations (Table 5; Supplementary Material C). Based on results of multiple linear regression analysis, electrum is one of the major hosts for $\mathrm{Au}$, consistent with studies of gold mineralogy at Olympic Dam [33]. In addition, association of $\mathrm{Au}$ with telluride NPs, either $\mathrm{Ag}-\mathrm{Bi}$ or $\mathrm{Bi}-\mathrm{Pb}$ can be inferred as seen elsewhere [24]. Therefore, the idea that 'invisible $\mathrm{Au}^{\prime}$ ' in pyrite is tied to As concentrations may be a bias of conducting analyses on pre-selected As-bearing pyrite grains.

\subsection{Trapping of Trace Elements during Ore Overprinting}

Sulphide ores in IOCG deposits, and particularly at Olympic Dam, can be also intimately associated with U-minerals [59-61] and $\mathrm{Pb}$-minerals formed from the radiogenic decay and subsequent migration of U. Lead is an element not commonly incorporated within the pyrite lattice. At Olympic Dam and other IOCG systems in the same ore province, $\mathrm{Pb}$ has been shown to be partly non-radiogenic and partly radiogenic, introduced at the time of deposit formation and as a result of the decay of uranium, respectively [42,62]. Fractures within pyrite, as in other sulphides, can act as suitable traps for remobilised $\mathrm{Pb}$ to combine with available $\mathrm{S}$, Se, and Te to form nanoparticulate galena, clausthalite [63] and altaite, and sometimes also anglesite. Upon healing and recrystallisation, these sub-micron- to nanoscale $\mathrm{Pb}$-phases become effectively included within pyrite, or as preserved as linear $\mathrm{Pb}$-bearing features within the grains that are observable by nanoSIMS isotope mapping $[64,65]$. The occurrence of such features likely indicates the role of trace element remobilisation and formation of inclusions during pyrite recrystallisation. Pyrite, a refractory mineral, is also likely to have acted as a physical trap for remobilised $\mathrm{Ag}, \mathrm{Bi}, \mathrm{Pb}$ and $\mathrm{Te}$, which subsequently can form $\mathrm{Ag}-(\mathrm{Au})$-tellurides, $\mathrm{Bi}-(\mathrm{Pb})-\mathrm{Ag}$-chalcogenides and other species.

Ores of the Olympic Dam deposit display evidence for multi-stage overprinting [33,43,44,59-61,66]. This has been observed for several mineral groups and is often expressed by the release of minor/trace impurities to form the same mineral with modified trace element signature and growth textures (e.g., hematite, uraninite), or formation of new minerals in close proximity to the parent phase. Ample evidence shows that sulphide minerals did not escape replacement, local-scale remobilisation and recrystallisation [60], even though key primary features are retained in $\mathrm{Cu}-\mathrm{Fe}$ sulphides [67]. Pyrite, like hematite and uraninite, is better suited to retain signatures of the multi-stage overprint. There is also evidence for pseudomorphic replacement (coupled dissolution-reprecipitation reactions; CDRR) retained by ore minerals from the Olympic Dam deposit [43,44,59]. Often, as seen for both oxides and sulphides, CDR-assisted replacement results in precipitation of new minerals in close 
spatial association with the replaced parent phase (e.g., sub-micron-scale molybdenite, scheelite, or uraninite NPs adjacent to replaced U-W-Sn-Mo-bearing hematite $[43,44,68]$.

PC2 features high loadings of Sn, predicting inclusions of cassiterite in many of the analysed pyrites. Other elements expected to be present as inclusions are $\mathrm{Cu}$ (chalcopyrite), $\mathrm{Zn}$ (sphalerite), and $\mathrm{Ti}$ (rutile). Concentrations of the contaminant heavy metals $\mathrm{Tl}$ and $\mathrm{Hg}$ in Olympic Dam pyrite are insignificantly low. The prediction of such a diverse range of inclusions within pyrite may relate to the complex reworking of primary zoning patterns in pyrite which results in the formation of an eclectic range of mineral phases that could range in size from a few microns down to true nanoparticles. Such an interpretation is consistent with the small grain size and assemblage complexity of ores at Olympic Dam [33].

\subsection{Impact of Left-Censored Data on the Interpretation of Statistical Analyses: Artefacts and False Interpretations}

Replacement of mdl values by a fixed value, or alternatively, taking the absolute values of detection limits, are likely to impact most statistical inference (Figure 2a,c). Multiple imputation is the most reliable method to deal with left-censored data, however taking a notional 'half the mdl value' for LA-ICP-MS datasets also gives visually plausible distributions of individual analyses (Figure $2 b, d$ ). We have, however, not investigated the effect of the latter on the results of statistical analyses due to our preferred adoption of quantitative imputation.

The consequent reduction of left-censored values within the data allows changes in the geochemical clusters, element groups and the strength of relationships between elements (e.g., between $\mathrm{Au}$ and associated elements), to be systematically tracked. The prediction of $\log (\mathrm{Au})$ concentration using the elements from the original $\mathrm{N}=4926$ dataset are likely dubious (Supplementary Material C; Table S7) due to the significant percentage of left-censored values-and amply illustrated by the hard-to-interpret dendrogram and PC1-PC2-PC3 projection (Figure 3a-d). The prediction of $\log (\mathrm{Au})$, obtained model coefficients and significance of predictors is questionable because the vast majority of elements, including those which would never be expected to correlate with $\mathrm{Au}$ (e.g., $\mathrm{Zn}$ or Ti), appeared as statistically significant, thus overestimating the strength of the relationship between $\mathrm{Au}$ and other elements in the $\mathrm{N}=4926$ dataset. On the other hand, a group of elements $\mathrm{Ag}, \mathrm{Se}, \mathrm{Te}, \mathrm{Bi}, \mathrm{Re},{ }^{204} \mathrm{~Pb}$ appear as significant predictors for $\log (\mathrm{Au})$ in both trimmed datasets $(\mathrm{N}=1501$ and $N=525)$, as well as in the original dataset, providing affirmation of the robustness of both types of multiple linear regressions (Supplementary Material C; Tables S8 and S9) and the genuine geochemical ties between $\mathrm{Au}$ and these elements. Similarly, throughout the statistical analyses, an association of $\mathrm{Ag}-\mathrm{Bi}-{ }^{\mathrm{X}} \mathrm{Pb}$ as Cluster 3 is recognised despite the data being incomplete (Figure 3a,c, Figure 4a,c and Figure 5a,c).

Despite the dubious predictions of Au using the original data, the $\mathrm{N}=4926$ dataset contains features that progressively disappear as the total number of analyses is reduced. Most importantly, the original dataset shows an inverse relationship between Ni and Co in Olympic Dam pyrite, elements which dominate the PC2 (Figure 3a), and likely indicates intra-grain heterogeneity in which absolute concentrations range over 2-3 orders of magnitude. K-means clustering applied to the original data revealed Cluster 1 which is specifically characterised by domains featuring very high $\mathrm{Co} / \mathrm{Ni}$ ratios of $\sim 100$ (Supplementary Material B). Neither is this geochemical clustering, nor such a significant inverse $\mathrm{Co}-\mathrm{Ni}$ relationship, identified from the k-means clustering of trimmed datasets. Moreover, within the trimmed data, the geochemical meaning of Clusters 1 and 2 is fundamentally changed.

Overall, the presence of a large percentage of left-censored data is shown to impact the results of statistical analysis and may consequently influence any interpretations drawn. The sequential trimming of data volume results in some of these features being dismissed as artefacts but also enables certain relationships among elements to be verified, thus allowing meaningful interpretations to be made. 


\subsection{Implications and Significance}

One of the main implications of this study lies in the demonstration of how reduction of the left-censored data alters the results of statistical analyses, suggesting that a careful approach should be taken when trimming datasets. Possible pitfalls, like overestimation of dependence among variables, or overlooking the significant relationship among variables, should be avoided.

Mineral chemistry studies on pyrite from IOCG deposits are limited despite the abundance of pyrite in these deposits, the ability of pyrite to scavenge metals and metalloids, and its refractory character allowing discrimination between different mineralisation events. Another contribution of this work lies in the quantitative data analysis of trace element signatures in pyrite from Olympic Dam. Multivariate statistical analyses, when considering such a large multi-element dataset, allows inferences to be made about the role of inclusion versus lattice-bound trace elements, and where suspected, the identity of those inclusions. One example is the $\mathrm{Ag}-\mathrm{Bi}-\mathrm{Pb}-(\mathrm{Au})$ trace element signature in pyrite and prediction of various telluride species and electrum as inclusions. Although the proportion of Au attributed to inclusions of electrum versus tellurides in pyrite is not directly quantifiable, the prediction of Au-bearing phases is not possible from bivariate scatterplots alone.

Further work, however, would require nanoscale characterisation of Au-(As)-bearing pyrite which will allow improved discrimination of nanoparticle populations and interpretation of their formation from lattice-bound elements or by other mechanisms.

\section{Conclusions}

This study, carried out blind without preselection of pyrite grains by texture, shows that multivariate statistical analysis can enable prediction but also expose bias and artefacts when defining trace element signatures in minerals from complex sulphide ores. The combination of multivariate statistical analyses shows that Olympic Dam pyrite is characterised by: (i) a Ag-Bi-Pb signature predicting inclusions of tellurides (as PC1); and (ii) highly variable Co-Ni ratios likely representing an oscillatory zonation pattern in pyrite (as PC2). Pyrite is a major host for As, Co and probably also Ni. The three elements do not correlate well at the grain-scale, indicating high variability in zonation patterns. Arsenic is not a good predictor for invisible Au at Olympic Dam. Most pyrites contain only negligible $\mathrm{Au}$, suggesting that invisible gold is not commonplace within the deposit. The data clearly show, however, that a small minority of pyrite grains analysed do contain Au-at noteworthy concentrations of tens and even hundreds of ppm, and moreover that this gold is correlated with $\mathrm{Ag}, \mathrm{Bi}, \mathrm{Pb}$ and Te. Such information is valuable for geometallurgical modelling and for derivation of qualitative deportment models of elements of interest.

The treatment of $<$ mdl values in large datasets with abundant left-censored data is critical, especially given the fact how replacement by an absolute or fixed value, i.e., median, can skew the data. The trimming of datasets with left-censored values should be done with caution as it potentially may result in overly large and erroneous correlations or dilution of those due to the significant reduction of analyses. The number of mdl values impacts on the outcome of statistical analyses and replacement of $<$ mdl values using multiple imputation is advised.

Supplementary Materials: The following are available online at http://www.mdpi.com/2075-163X/10/1/61/s1, Supplementary Material A: Sequential binary partitioning of the data into corresponding ilr-coordinates (Tables S1-S3). K-means clustering validation via Silhouette widths and 'elbow' plots (Figures S1-S3). Supplementary Material B: Summary Statistics (in ppm) for three clusters obtained via k-means algorithm (Tables S4-S6). Supplementary Material C: Results from regression of $\log (\mathrm{Au})$ for the ilr-coordinates of the remaining elements (Tables S7-S9).

Author Contributions: The research described was carried out by M.D. on datasets obtained by K.E., M.K. and V.S.K., with guidance provided by A.V.M. and S.G. The research was supervised by C.L.C. and K.E. and the paper written by M.D., N.J.C., C.L.C. and K.E. All authors have read and agreed to the published version of the manuscript.

Funding: This research was funded through the project "Trace elements in Fe-oxides: deportment, distribution and application in ore genesis, geochronology, exploration and mineral processing", supported by BHP Olympic Dam 
and the South Australian Government Mining and Petroleum Services Centre of Excellence. N.J.C. acknowledges additional support from the ARC Research Hub for Australian Copper-Uranium (Grant IH130200033). V.K. acknowledges funding from the ARC Linkage Grant "The supergiant Olympic Dam U-Cu-Au-REE ore deposit: towards a new genetic model" (Linkage Grant LP130100438).

Acknowledgments: We appreciate the insightful comments of three anonymous reviewers, which have helped us better formulate results and interpretations.

Conflicts of Interest: The authors declare no conflict of interest.

\section{References}

1. Vaughan, D.J.; Corkhill, C.L. Mineralogy of Sulphides. Elements 2017, 13, 81-87. [CrossRef]

2. Craig, J.R.; Vokes, F.M.; Solberg, T.N. Pyrite: Physical and chemical textures. Miner. Depos. 1998, 34, 82-101. [CrossRef]

3. Carstens, C.W. Om geokjemiske undersøkelser av malmer. Norsk Geol. Tidsskr. 1941, 21, $213-221$.

4. Fleischer, M. Minor Elements in Some Sulphide Minerals. In Economic Geology Fiftieth Anniversary, Volume 1905-1955; Bateman, A.M., Ed.; Economic Geology Publishing Company: Urbana, IL, USA, 1955; pp. 970-1024.

5. Hawley, J.E.; Nichol, I. Trace elements in pyrite, pyrrhotite and chalcopyrite of different ores. Econ. Geol. 1961, 56, 467-487. [CrossRef]

6. Gregory, D.D.; Lyons, T.W. The effects of trace element content on pyrite oxidation rates. In Proceedings of the American Geophysical Union Fall Meeting, New Orleans, LA, USA, 11-15 December 2017. 2017AGUFM.H41I1554G.

7. Abraitis, P.K.; Pattrick, R.A.D.; Vaughan, D.J. Variations in the Compositional, Textural and Electrical Properties of Natural Pyrite: A Review. Int. J. Miner. Process. 2004, 74, 41-59. [CrossRef]

8. Large, R.R.; Maslennikov, V.V.; Robert, V.; Danyushevsky, L.V.; Chang, Z.S. Multistage sedimentary and metamorphic origin of pyrite and gold in the giant Sukhoi Log deposit, Lena Gold Province, Russia. Econ. Geol. 2007, 102, 1233-1267. [CrossRef]

9. Large, R.R.; Danyushevsky, L.D.; Hollit, C.; Maslennikov, V.V.; Meffre, S.; Gilbert, S.; Bull, S.; Scott, R.; Emsbo, P.; Thomas, H.; et al. Gold and trace element zonation in pyrite using a laser imaging technique; implications for the timing of gold in orogenic and Carlin-style sediment-hosted deposits. Econ. Geol. 2009, 104, 635-668. [CrossRef]

10. Sung, Y.H.; Brugger, J.; Ciobanu, C.L.; Pring, A.; Skinner, W.; Nugus, M. Invisible gold in arsenian pyrite and arsenopyrite from a multistage Archaean gold deposit: Sunrise Dam, Eastern Goldfields Province, Western Australia. Miner. Depos. 2009, 44, 765-791. [CrossRef]

11. Cook, N.J.; Ciobanu, C.L.; Mao, J. Textural control on gold distribution in As-free pyrite from the Dongping, Huangtuliang and Hougou gold deposits, North China Craton (Hebei Province, China). Chem. Geol. 2009, 264, 101-121. [CrossRef]

12. Thomas, H.V.; Large, R.R.; Bull, S.W.; Maslennikov, V.; Berry, R.F.; Frazer, R.; Froud, F.; Moye, R. Pyrite and pyrrhotite textures and composition in sediments, laminated quartz veins, and reefs at Bendigo Gold Mine, Australia: Insights for ore genesis. Econ. Geol. 2011, 106, 1-31. [CrossRef]

13. Cook, N.J.; Ciobanu, C.L.; Meria, D.; Silcock, D.; Wade, B.P. Arsenopyrite-Pyrite Association in an Orogenic Gold Ore: Tracing Mineralization History from Textures and Trace Elements. Econ. Geol. 2013, 108, 1273-1283. [CrossRef]

14. Cook, N.J.; Chryssoulis, S.L. Concentrations of invisible gold in the common sulphides. Can. Mineral. 1990, 28, 1-16.

15. Reich, M.; Kesler, S.E.; Utsunomiya, S.; Palenik, C.S.; Chryssoulis, S.L.; Ewing, R.C. Solubility of gold in arsenian pyrite. Geochim. Cosmochim. Acta 2005, 69, 2781-2796. [CrossRef]

16. Deditius, A.P.; Reich, M. Constraints on the solid solubility of $\mathrm{Hg}$, $\mathrm{Tl}$, and $\mathrm{Cd}$ in arsenian pyrite. Am. Mineral. 2016, 101, 1451-1459. [CrossRef]

17. George, L.L.; Biagioni, C.; D’Orazio, M.; Cook, N.J. Textural and trace element evolution of pyrite during greenschist facies metamorphic recrystallization in the southern Apuan Alps (Tuscany, Italy): Influence on the formation of Tl-rich sulfosalt melt. Ore Geol. Rev. 2018, 102, 59-105. [CrossRef]

18. George, L.; Biagioni, C.; Lepore, G.O.; Lacalamita, M.; Agrosì, G.; Capitani, G.C.; Bonaccorsi, E.; D’Acapito, F. The speciation of thallium in (Tl, Sb, As)-rich pyrite. Ore Geol. Rev. 2019, 107, 364-380. [CrossRef] 
19. Cook, N.J.; Ciobanu, C.L.; George, L.; Zhu, Z.-Y.; Wade, B.; Ehrig, K. Trace Element Analysis of Minerals in Magmatic-Hydrothermal Ores by Laser Ablation Inductively-Coupled Plasma Mass Spectrometry: Approaches and Opportunities. Minerals 2016, 6, 111. [CrossRef]

20. Ciobanu, C.L.; Verdugo-Ihl, M.R.; Slattery, A.; Cook, N.J.; Ehrig, K.; Courtney-Davies, L.; Wade, B.P. Silician magnetite: Si-Fe nanoprecipitates and other mineral inclusions in magnetite from the Olympic Dam deposit, South Australia. Minerals 2019, 9, 311. [CrossRef]

21. Xu, J.; Ciobanu, C.L.; Cook, N.J.; Slattery, A.D. Crystals from the Powellite-Scheelite Series at the Nanoscale: A Case Study from the Zhibula Cu Skarn, Gangdese Belt, Tibet. Minerals 2019, 9, 340. [CrossRef]

22. Keyser, W.; Ciobanu, C.L.; Cook, N.J.; Feltus, H.; Johnson, G.; Slattery, A.; Wade, B.P.; Ehrig, K. Mineralogy of Zirconium in Iron-Oxides: A Micron- to Nanoscale Study of Hematite Ore from Peculiar Knob, South Australia. Minerals 2019, 9, 244. [CrossRef]

23. Van Tendeloo, G.; Bals, S.; Van Aert, S.; Verbeeck, J.; Van Dyck, D. Advanced electron microscopy for advanced materials. Adv. Mater. 2012, 24, 5655-5675. [CrossRef]

24. Ciobanu, C.L.; Cook, N.J.; Utsunomiya, S.; Kogagwa, M.; Green, L.; Gilbert, S.; Wade, B. Gold-telluride nanoparticles revealed in arsenic-free pyrite. Am. Mineral. 2012, 97, 1515-1518. [CrossRef]

25. Ciobanu, C.L.; Cook, N.J.; Maunders, C.; Wade, B.P.; Ehrig, K. Focused ion beam and advanced electron microscopy for minerals: Insights and outlook from bismuth sulphosalts. Minerals 2016, 6, 112. [CrossRef]

26. Winderbaum, L.; Ciobanu, C.L.; Cook, N.J.; Paul, M.; Metcalfe, A.; Gilbert, S. Multivariate Analysis of an LA-ICP-MS Trace Element Dataset for Pyrite. Mathem. Geosci. 2012, 44, 823-842. [CrossRef]

27. Dmitrijeva, M.; Metcalfe, A.V.; Ciobanu, C.L.; Cook, N.J.; Frenzel, M.; Keyser, W.M.; Johnson, G.; Ehrig, K. Discrimination and Variance Structure of Trace Element Signatures in Fe-Oxides: A Case Study of BIF-Mineralisation from the Middleback Ranges, South Australia. Math. Geosci. 2018, 50, 381-415. [CrossRef]

28. Dmitrijeva, M.; Ehrig, K.; Ciobanu, C.L.; Cook, N.J.; Verdugo-Ihl, M.R.; Metcalfe, A. Defining IOCG signatures through compositional data analysis: A case study of lithogeochemical zoning from the Olympic Dam deposit, South Australia. Ore Geol. Rev. 2019, 105, 86-101. [CrossRef]

29. Dmitrijeva, M.; Ehrig, K.; Ciobanu, C.L.; Cook, N.J.; Verdugo-Ihl, M.R.; Metcalfe, A. Mineralization-alteration footprints in the Olympic Dam IOCG district, South Australia: The Acropolis prospect. J. Geochem. Explor. 2019, 205, 106333. [CrossRef]

30. Palarea-Albaladejo, J.; Martin-Fernandez, J.A. Values below detection limit in compositional chemical data. Anal. Chim. Acta 2013, 764, 32-43. [CrossRef]

31. Palarea-Albaladejo, J.; Martin-Fernandez, J.A. ZCompositions-R package for multivariate imputation of left-censored data under a compositional approach. Chemom. Intell. Lab. Syst. 2015, 143, 85-96. [CrossRef]

32. Hron, K.; Templ, M.; Filzmoser, P. Imputation of missing values for compositional data using classical and robust methods. Comput. Stat. Data Anal. 1986, 54, 3095-3107. [CrossRef]

33. Ehrig, K.; McPhie, J.; Kamenetsky, V.S. Geology and mineralogical zonation of the Olympic Dam Iron Oxide $\mathrm{Cu}-\mathrm{U}-\mathrm{Au}-\mathrm{Ag}$ deposit, South Australia. In Geology and Genesis of Major Copper Deposits and Districts of the World: A Tribute to Richard H. Sillitoe; Society of Economic Geologists Special Publication: Littleton, CO, USA, 2012; Volume 16, pp. 237-267.

34. Foster, A.R.; Williams, P.; Ryan, C. Distribution of Gold in Hypogene Ore at the Ernest Henry Iron Oxide Copper-Gold Deposit, Cloncurry District, NW Queensland. Explor. Mining Geol. 2007, 16, 125-143. [CrossRef]

35. Rusk, B.; Oliver, N.; Cleverley, J.; Blenkinsop, T.; Dexian, Z.; Patrick, P.; Habermann, P. Physical and chemical characteristics of the Ernest Henry iron oxide copper gold deposit, Australia; implications for IOGC genesis. In Hydrothermal Iron Oxide Copper-Gold \& Related Deposits: A Global Perspective-Advances in the Understanding of IOCG Deposits; Porter, T.M., Ed.; Global Perspective Series 3; PGC Publishing: Linden Park, Australia, 2010; pp. 201-218.

36. Reich, M.; Simon, A.C.; Deditius, A.; Barra, F.; Chryssoulis, S.; Lagas, G.; Tardani, D.; Knipping, J.; Bilenker, L.; Sánchez-Alfaro, P.; et al. Trace Element Signature of Pyrite from the Los Colorados Iron Oxide-Apatite (IOA) Deposit, Chile: A Missing Link Between Andean IOA And Iron Oxide Copper-Gold Systems? Econ. Geol. 2016, 111, 743-761. [CrossRef] 
37. Gregory, D.D.; Cracknell, M.J.; Large, R.R.; McGoldrick, P.; Kuhn, S.; Maslennikov, V.V.; Baker, M.J.; Fox, N.; Belousov, I.; Figueroa, M.C.; et al. Distinguishing Ore Deposit Type and Barren Sedimentary Pyrite Using Laser Ablation-Inductively Coupled Plasma-Mass Spectrometry Trace Element Data and Statistical Analysis of Large Data Sets. Econ. Geol. 2019, 114, 771-786. [CrossRef]

38. Román, N.; Reich, M.; Leisen, M.; Morata, D.; Barra, F.; Deditius, A.P. Geochemical and micro-textural fingerprints of boiling in pyrite. Geochim. Cosmochim. Acta 2019, 246, 60-85. [CrossRef]

39. Elghali, A.; Benzaazoua, M.; Bussière, B.; Genty, T. Spatial Mapping of Acidity and Geochemical Properties of Oxidized Tailings within the Former Eagle/Telbel Mine Site. Minerals 2019, 9, 180. [CrossRef]

40. Danyushevsky, L.V.; Robinson, P.; Gilbert, S.; Norman, M.; Large, R.; McGoldrick, P.; Shelley, J.M.G. Routine quantitative multi-element analysis of sulphide minerals by laser ablation ICP-MS: Standard development and consideration of matrix effects. Geochem. Explor. Environ. Anal. 2011, 11, 51-60. [CrossRef]

41. Norris, A.; Danyushevsky, L. Towards Estimating the Complete Uncertainty Budget of Quantified Results Measured by LA-ICP-MS; Goldschmidt: Boston, MA, USA, 2018.

42. Schmandt, D.S. Mineralogical Distributions of Radionuclides in Copper-Uranium Ores from Olympic Dam, South Australia. Ph.D. Thesis, The University of Adelaide, Adelaide, Australia, 2019. Unpublished.

43. Ciobanu, C.L.; Wade, B.P.; Cook, N.J.; Schmidt Mumm, A.; Giles, D. Uranium-bearing hematite from the Olympic Dam Cu-U-Au deposit, South Australia; a geochemical tracer and reconnaissance $\mathrm{Pb}-\mathrm{Pb}$ geochronometer. Precambr. Res. 2013, 238, 129-147. [CrossRef]

44. Verdugo-Ihl, M.R.; Ciobanu, C.L.; Cook, N.J.; Ehrig, K.; Courtney-Davies, L.; Gilbert, S. Textures and $\mathrm{U}-\mathrm{W}-\mathrm{Sn}-\mathrm{Mo}$ signatures in hematite from the $\mathrm{Cu}-\mathrm{U}-\mathrm{Au}-\mathrm{Ag}$ orebody at Olympic Dam, South Australia: Defining the archetype for IOCG deposits. Ore Geol. Rev. 2017, 91, 173-195. [CrossRef]

45. Aitchison, J. The Statistical Analysis of Compositional Data. In Monographs on Statistics and Applied Probability; Chapman \& Hall: London, UK, 1986; p. 416. [CrossRef]

46. Pawlowsky-Glahn, V.; Egozcue, J.J.; Tolosana-Delgado, R. Modeling and Analysis of Compositional Data; Wiley: Chichester, UK, 2015; p. 272. [CrossRef]

47. van den Boogart, K.G.; Tolosana-Delgado, R.; Bren, M. Compositions: Compositional Data Analysis. R Package Version 1.40-2. 2018. Available online: https://CRAN.R-project.org/package=compositions (accessed on 8 January 2020).

48. Egozcue, J.J.; Pawlowsky-Glahn, V.; Mateu-Figueras, G.; Barceló-Vidal, C. Isometric logratio transformations for compositional data analysis. Math. Geol. 2003, 35, 279-300. [CrossRef]

49. Egozcue, J.J.; Pawlowsky-Glahn, V. Simplicial Geometry for Compositional Data. In Compositional Data Analysis in the Geosciences: From Theory to Practice; Buccianti, A., Mateu-Figueras, G., Pawlowsky-Glahn, V., Eds.; Special Publications; Geological Society: London, UK, 2006; Volume 264, pp. 145-159. [CrossRef]

50. Aitchison, J.; Barceló-Vidal, C.; Pawlowsky-Glahn, V. Some comments on compositional data analysis in archaeometry, in particular the fallacies in Tangri and Wright's dismissal of logratio analysis. Archaeometry 2002, 44, 295-304. [CrossRef]

51. Mathieu, L. Detecting magmatic-derived fluids using pyrite chemistry: Example of the Chibougamau area, Abitibi Subprovince, Québec. Ore Geol. Rev. 2019, 114, 103127. [CrossRef]

52. Caciagli, N. Multielement Geochemical Modelling for Mine Planning: Case Study from an Epithermal Gold Deposit. In Compositional Data Analysis; Martín-Fernández, J.A., Thió-Henestrosa, S., Eds.; Springer: Berlin, Germany, 2016; Volume 187, pp. 45-61. [CrossRef]

53. Gabriel, K.R. The biplot graphical display of matrices with application to principal component analysis. Biometrika 1971, 58, 453-467. [CrossRef]

54. Templ, M.; Hron, K.; Filzmoser, P. robCompositions: An R-Package for Robust Statistical Analysis of Compositional Data. In Compositional Data Analysis. Theory and Applications; Pawlowsky-Glahn, V., Buccianti, A., Eds.; John Wiley \& Sons: Chichester, UK, 2018; pp. 341-355. [CrossRef]

55. Filsmozer, P.; Hron, K.; Templ, M. Applied Compositional Data Analysis with Worked Examples in R; Springer: New York, NY, USA, 2018; p. 280. [CrossRef]

56. Bowles, J.F.W.; Howie, R.A.; Vaughan, D.J.; Zussman, J. Non-silicates: Volume 5A. In Rock-Forming Minerals; Deer, W.A., Howie, R.A., Zussman, J., Eds.; Geological Society: London, UK, 2011; p. 920.

57. Barton, M.D. Iron oxide (-Cu-Au-REE-P-Ag-U-Co) systems. In Treatise on Geochemistry, 2nd ed.; Holland, H.D., Turekian, K.K., Eds.; Elsevier: Oxford, UK, 2014; pp. 515-541. [CrossRef] 
58. Li, R.; Chen, H.; Xia, X.; Yang, Q.; Danyushevsky, L.D.; Lai, C. Using integrated in-situ sulphide trace element geochemistry and sulfur isotopes to trace ore-forming fluids: Example from the Mina Justa IOCG deposit (southern Perú). Ore Geol. Rev. 2018, 101, 165-179. [CrossRef]

59. Macmillan, E.; Cook, N.J.; Ehrig, K.; Ciobanu, C.L.; Pring, A. Uraninite from the Olympic Dam IOCG-U-Ag deposit: Linking textural and compositional variation to temporal evolution. Am. Mineral. 2016, 101, 1295-1320. [CrossRef]

60. Macmillan, E.; Ehrig, K.; Ciobanu, C.L.; Cook, N.J.; Pring, A. Replacement of uraninite by bornite via coupled dissolution-reprecipitation: Evidence from texture and microstructure. Can. Mineral. 2016, 54, 1369-1383. [CrossRef]

61. Macmillan, E.; Cook, N.J.; Ehrig, K.; Pring, A. Chemical and textural interpretation of late-stage coffinite and brannerite from the Olympic Dam IOCG-Ag-U deposit. Mineral. Mag. 2017, 81, 1323-1366. [CrossRef]

62. Owen, N.D. The Mineralogical Deportment of Radionuclides in South Australian Cu-Au-(U) Ores. Ph.D. Thesis, The University of Adelaide, Adelaide, Australia, 2019. Unpublished.

63. Owen, N.D.; Ciobanu, C.L.; Cook, N.J.; Slattery, A.D.; Basak, A.K. Nanoscale Study of Clausthalite-Bearing Symplectites in $\mathrm{Cu}-\mathrm{Au}-(\mathrm{U})$ Ores: Implications for Ore Genesis. Minerals 2018, 8, 67. [CrossRef]

64. Rollog, M.; Cook, N.J.; Guagliardo, P.; Ehrig, K.; Ciobanu, C.L.; Kilburn, M. Detection of Trace Elements/Isotopes in Olympic Dam Copper Concentrates by nanoSIMS. Minerals 2019, 9, 336. [CrossRef]

65. Rollog, M.; Cook, N.J.; Guagliardo, P.; Ehrig, K.; Kilburn, M. Radionuclide distributions in Olympic Dam copper concentrates: The significance of minor hosts, incorporation mechanisms, and the role of mineral surfaces. Minerals Eng. 2020, 148, 106176. [CrossRef]

66. Owen, N.D.; Cook, N.J.; Rollog, M.; Ehrig, K.J.; Schmandt, D.S.; Ram, R.; Brugger, J.; Ciobanu, C.L.; Wade, B.; Guagliardo, P. REE-, Sr-, Ca-aluminum-phosphate-sulfate minerals of the alunite supergroup and their role as hosts for radionuclides. Am. Mineral. 2019, 104, 1806-1819. [CrossRef]

67. Ciobanu, C.L.; Cook, N.J.; Ehrig, K. Ore minerals down to the nanoscale: $\mathrm{Cu}-(\mathrm{Fe})$-sulphides from the iron oxide copper gold deposit at Olympic Dam, South Australia. Ore Geol. Rev. 2017, 81, 1218-1235. [CrossRef]

68. Cook, N.J.; Ciobanu, C.L.; Ehrig, K.; Slattery, A.; Verdugo-Ihl, M.R.; Courtney-Davies, L.; Gao, W. Advances and opportunities in ore mineralogy. Minerals 2017, 7, 233. [CrossRef]

(C) 2020 by the authors. Licensee MDPI, Basel, Switzerland. This article is an open access article distributed under the terms and conditions of the Creative Commons Attribution (CC BY) license (http://creativecommons.org/licenses/by/4.0/). 